$$
\text { DOE/NV/10338--T1 }
$$

\title{
Aromatic Hydrocarbons Associated With Brines From Geopressured Wells
}

Contract No. DE-AS08-83NV10338

\section{Annual Report - Fiscal 1985}

Dean F. Keeley and John R. Meriwether

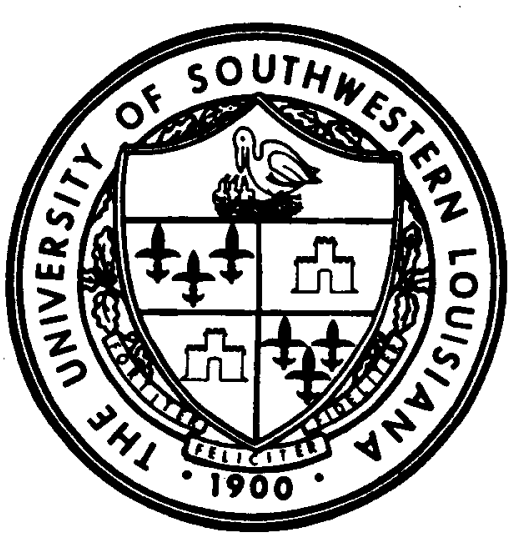

Energy Studies

Environmental Studies

\section{ACADIANA RESEARCH LABORATORY}




\section{DISCLAIMER}

This report was prepared as an account of work sponsored by an agency of the United States Government. Neither the United States Government nor any agency Thereof, nor any of their employees, makes any warranty, express or implied, or assumes any legal liability or responsibility for the accuracy, completeness, or usefulness of any information, apparatus, product, or process disclosed, or represents that its use would not infringe privately owned rights. Reference herein to any specific commercial product, process, or service by trade name, trademark, manufacturer, or otherwise does not necessarily constitute or imply its endorsement, recommendation, or favoring by the United States Government or any agency thereof. The views and opinions of authors expressed herein do not necessarily state or reflect those of the United States Government or any agency thereof. 


\section{DISCLAIMER}

Portions of this document may be illegible in electronic image products. Images are produced from the best available original document. 
$\mathrm{DOE} / \mathrm{NV} / 10338--\mathrm{T} 1$

DE86 007472

\section{AROMATIC HYDROCARBONS ASSOCIATED WITH BRINES FROM GEOPRESSURED WELLS}

Contract No. DE-AS08-83Nv10338
Dean F. Reeley and John R. Meriwether
University of Southwestern Louisiana
Lafayette, Louisiana 70504

ANRUAL REPORT - FISCAL 1985

\section{DISCLAIMER}

This report was prepared as an account of work sponsored by an agency of the United States Government. Neither the United States Government nor any agency thereof, nor any of their employees, makes any warranty, express or implied, or assumes any legal liability or responsibility for the accuracy, completeness, or usefulness of any information, apparatus, product, or process disclosed, or represents that its. use would not infringe privately owned rights. Reference herein to any specific commercial product, process, or service by trade name, trademark, manufacturer, or otherwise does not necessarily constitute or imply its endorsement, recommendation, or favoring by the United States Government or any agency thereof. The views and opinions of authors expressed herein do not necessarily state or reflect those of the United States Government or any agency thereof. 


\section{AROMATIC HYDROCARBONS ASSOCIATED WITH BRINES \\ FROM GEOPRESSURED WELLS \\ Contract No. DE-AS08-83NV10338 \\ Dean F. Keeley and John R. Meriwether \\ University of Southwestern Louisiana \\ Lafayette, Louisiana 70504}

\section{Abstract}

Samples of cryocondensates -- materials condensed at 78.5 degrees centigrade -- were taken on a regular basis from the gas stream from the USDOE geopressured wells. Most of the data has been taken from the Gladys McCall well as it has flowed on a regular and almost continous basis. The cryocondensates, not the "condensate" from gas wells, are almost exclusively aromatic hydrocarbons, primarily benzene, toluene, ethylbenzene, and the xylenes, but contain over 95 compounds, characterized using gas chromatographic-mass spectroscopy.

The yield of the cryocondensates from the Gladys McCall well steadily increased as a function of the production volume -- from 17.0 to 40.5 microliters/liter of brine during the production of 7.14 million barrels of brine. The yield dropped and became erratic when the well began to produce a heavy oil. After about five months, oil production ceased and the yield of cryocondensates has again increased.

The solubility in water and brine of benzene, toluene, ethylbenzene and o-xylene, some of the components of the cryocondensate, as well as distribution coefficients between 
water or brine and a standard oil have been measured.

Samples of brine from commercial oil and/or gas wells have been taken and analyzed; thus far no compounds of the types in the cryocondensates have been found.

\section{Introduction}

Early in the study of the gas from the DOW-DOE L. R. Sweezy \#1 geopressured well a sample of gas from the well was analyzed by gas chromatographic-mass spectrometry (GCMS). This analysis indicated the presence of trace amounts of a number of hydrocarbons in the gas with molecular weights greater than the $\mathrm{C}-1$ to $\mathrm{C}-5$ species that were being determined at the well site by conventional gas-liquid chromatography (GLC). Interest in these observations prompted a sampling of what are now known as "cryocondensate" hydrocarbons from the gas stream. The collection of the cryocondensates was accomplished by passing a portion of the separator gas ( $1 \%)$ through a series of ice-water, dryice/acetone traps. Analysis by GLC showed that the cryocondensate consisted primarily of aromatic compounds. Encouraged by this discovery, the gas streams at the pleasant Bayou \#2 and the Gladys McCall \#1 wells were sampled. Eventhough these wells are located at significantly different locations and completed in different zones, the cryocondensates were almost identical in composition. The gas chromatograms for the cryocondensates from the three wells are 


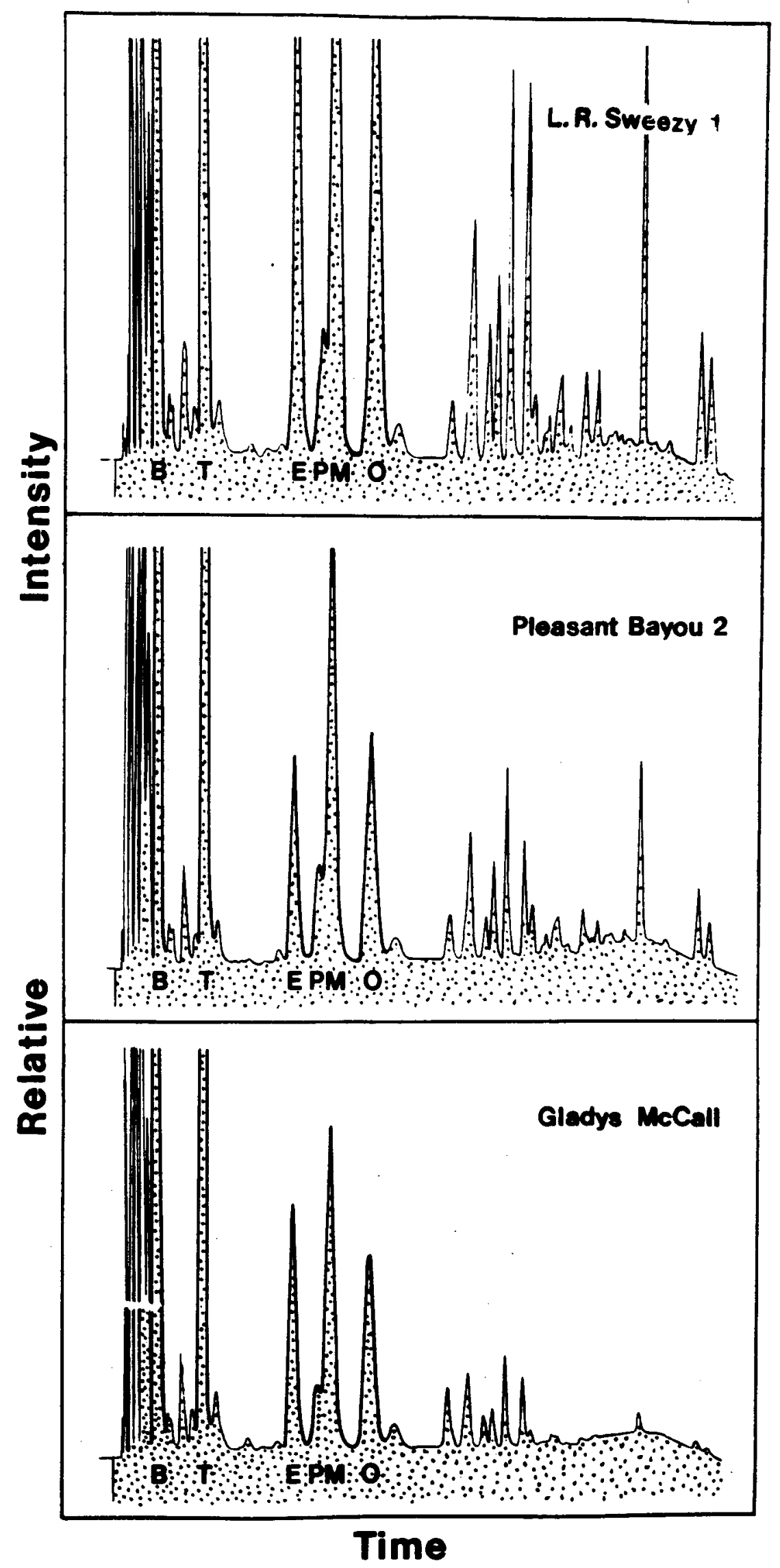

Figure 1 
shown in Figure 1.

There was a clear indication that the amount of heavier hydrocarbons produced in the Sweezy well increased during its later life, culminating in the production of heavy crude oil just prior to sanding-up.

During the past year, research has continued concerning the hydrocarbons first described in detail at the sweezy We11. The research is divided into six TASRS as described when this research was proposed:

Task 1: Distribution Coefficient Measurements

Task 2: Depleted 0il and Gas Wells

Task 3: DOE Well Sampling

Task 4: Well Sample Analysis

Task 5: Aliphatic Hydrocarbon Monitoring

Task 6: $\mathrm{C}-12 / \mathrm{C}-13$ Isotope Ratios

The following sections of this report will consider the procedures, data analysis and results for these tasks.

\section{TASR 1: DISTRIBUTION COEFFICIENT AND SOLUBILITY DETERMINATIONS :}

During this past year the solubilities of benzene, toluene, ethylbenzene and o-xylene in water and sodium chloride solutions of up to $5.0 \mathrm{M}$ have been determined along with the distribution coefficients of the compound between the solution and a standard "oil", both at 25 C. Mobil-1, a synthetic oil, was chosen as a standard since it has a 
constant formulation. The details of the head-space analysis methodology and the results of the measurements on benzene and toluene are presented in the attached copy of a paper which has been submitted to DOE for review prior to publication. The similar data for ethylbenzene and the isomers of xylene is being determined and will be ready for publication during the next few months.

Since a head-space analysis attachment of the type needed was not available for the Varian model 3700 gas chromatograph, one was designed and built. A description of the attachment has been prepared for publication and submitted to DOE for review - a copy is appended to this report.

\section{TASR 2: DEPLETED OIL AND GAS WELLS}

Actually, this task should perhaps have been titled "Water Producing Commercial Gas/Oil Wells" since depleted wells are usually no longer available to be sampled. To date, five producing gas/oil wells which are making large quantities of brine have been sampled. Brine and conventional condensate samples were collected from all wells. No aromatic compounds have been found in any of the samples, in sharp contrast to samples from the DOE geopressured wells. The production zones of the sampled wells range from 6745 to 9278 feet deep. The absence of the C-6 through C-8 aromatic hydrocarbons from these wells, which are all above the geopressured zone, seems to indicate either a higher temper- 
ature requirement for production of aromatic hydrocarbons or the selective removal of the aromatics, probably by partition between phases during hydrocarbon migration.

\section{TASK 3: DOE WELL SANPIING}

Samples have been taken regularly from the Gladys McCall well, the only currently operational design well. A portion of the gas stream is diverted through a cryogenic system to obtain the compounds of interest.

A Victor Model SGS-111 stainless steel two stage regulator was modified to connect to the main gas line been the gas-brine separator and the gas-cooler at the Gladys McCall well. All parts used in the modification, except for the gas trap, were stainless steel and rated at 3000 psi. The regulator served both to reduce the gas pressure and to control the flow rate; the later being accomplished by the stainless steel needle valve attached to the regulator. The gas from the regulator was passed through three (3) 2 in. o.d. by 13 in. long, Pyrex glass traps which were immersed in acetone/dry-ice baths. The traps were serially connected to each other and to the regulator by means of $1 / 4$ in. $0 . d$. Teflon tubing. Connections were made using $1 / 4$ in. nylon or stainless steel Swagelok fittings. The last trap was serially connected to a calibrated, American Meter Co. model Al-18 stainless steel wet-test meter. Prior to sample collection, gas was allowed to flow through the system at a moderate 
rate for at least 10 minutes in order to purge the system and saturate, with gas, the deionized water used in the wet test meter. When in operation the gas flow rate was maintained at $16-20 \mathrm{cu} . \mathrm{ft} . / \mathrm{hr}$. A minimum of $60 \mathrm{cu}$. ft. of gas was sampled during each well visit.

During the mid-point of the gas sampling, two (2) gallons of chilled brine were slowly collected in glass jugs by passing brine from a valve located on the brine exit line of the separator through a coiled twenty (20) foot length of $1 / 4$ in. stainless steel tubing immersed in a crushed ice/water mixture. The jugs were closed with tin lined caps immediately after filling to keep possible loss, by evaporation, of residual hydrocarbons in the brine to a minimum.

When the gas sampling was complete, the glass traps were sealed with Parafilm and placed in a Dry-ice containing ice box for transport to the university laboratory for analysis. Upon arriving at the university the contents of the traps were immediately thawed, poured from the traps and combined, their total volume was measured and then placed in sma11, labeled bottle for further analysis. Any material remaining in the traps was removed with several small hexane washes. The washes were combined in a $50 \mathrm{~mL}$ volumetric flask and made up to the mark with hexane. The residual hydrocarbons of interest (cryocondensate) remaining in the brine were extracted from a one (1) liter aliquot of brine using approximately twenty (20) milliliters of hexane. The 
hexane layer was separated from the brine and transferred to a $25 \mathrm{~mL}$ volumetric flask and made up to the mark with hexane.

\section{TASR 4: WELI SAMPLE ANALYSIS}

All analyses of the cryocondensate, the traps wash solution, and the brine extract solution were made using a Varian model 3700 gas chromatograph equipped with a flame ionization detector (FID). The hydrogen and air flow rates were 30 and $300 \mathrm{~mL} / \mathrm{min}$. respectively. Helium was used as a carrier gas at a flow rate of $30 \mathrm{~mL} / \mathrm{min}$. Integration of the areas under the chromatograms was accomplished by a Varian model CDS-111 data system attached to the output of the FID. A graph was simultaneously produced on a Varian model 9176 recorder. Component separation was accomplished by using a 6 ft. $5.0 \%$ SP-1200/1.75\% Bentone 34 on $100 / 200$ Supelcoport column (Supelco, Inc.). For analysis of the cryocondensate, temperature programming was used: (ie $60 \mathrm{c} / 14 \mathrm{~min}$ / / 10 C/min. / 170 C / 10 min.). Relative FID sensitivity factors given by Dietz ( $\mathrm{J}$, Gas Chrom,.68, 5 (1967)) were used to obtain normalized percents of the six predominant components (ie. benzene, toluene, ethylbenzene, ortho-, meta-, and para-xylenes). Quantitative analysis of the wash and extract solutions were done isothermally at $60 \mathrm{C}$ using a $3 \mathrm{ft}$. bentone-34 column and standard curves which were obtained by using prepared solutions of the hydrocarbons in hexane. 
Table I and Figure 2 present the results obtained for the concentration of the cryocondensates from the DOE-TF \& $S$ Gladys McCa11 \#1 well. The concentration expressed as microliters of cryocondensate per liter of brine (ie. ppm on a volume basis), is given as a function of cumulative brine production rather than time of production which would not account for shut-in time of the well. 
TABLE I. Cryocondensate from DOE-TF \& S Gladys McCal1 \#1 Well.

Cumulative Brine Volume

Date

$10 / 10 / 83$

$12 / 12 / 83$

$2 / 3 / 84$

$3 / 21 / 84$

$5 / 24 / 84$

$6 / 13 / 84$

$7 / 9 / 84$

$8 / 23 / 84$

$10 / 12 / 84$

$11 / 26 / 84$

$12 / 28 / 84$

$1 / 30 / 85$

$2 / 18 / 85$

$3 / 22 / 85$

$4 / 29 / 85$

$5 / 5 / 85$

$7 / 16 / 85$

$8 / 26 / 85$

$10 / 5 / 85$
(Megabarre1s)

0.038

0.450

1.387

2.112

2.345

2.981

3.508

4.318

5.063

5.798

6.350

6.847

7.140

7.528

7.964

8.465

9.312

10.416

11.624
Cryocondensate

(Microliters/liter
17.02

24.2

17.96

27.79

28.47

30.29

30.81

34.12

33.90

31.04

38.34

35.79

40.55

34.83

32.14

33.11

29.78

32.70

36.76 


\section{Gladys McCall Well}

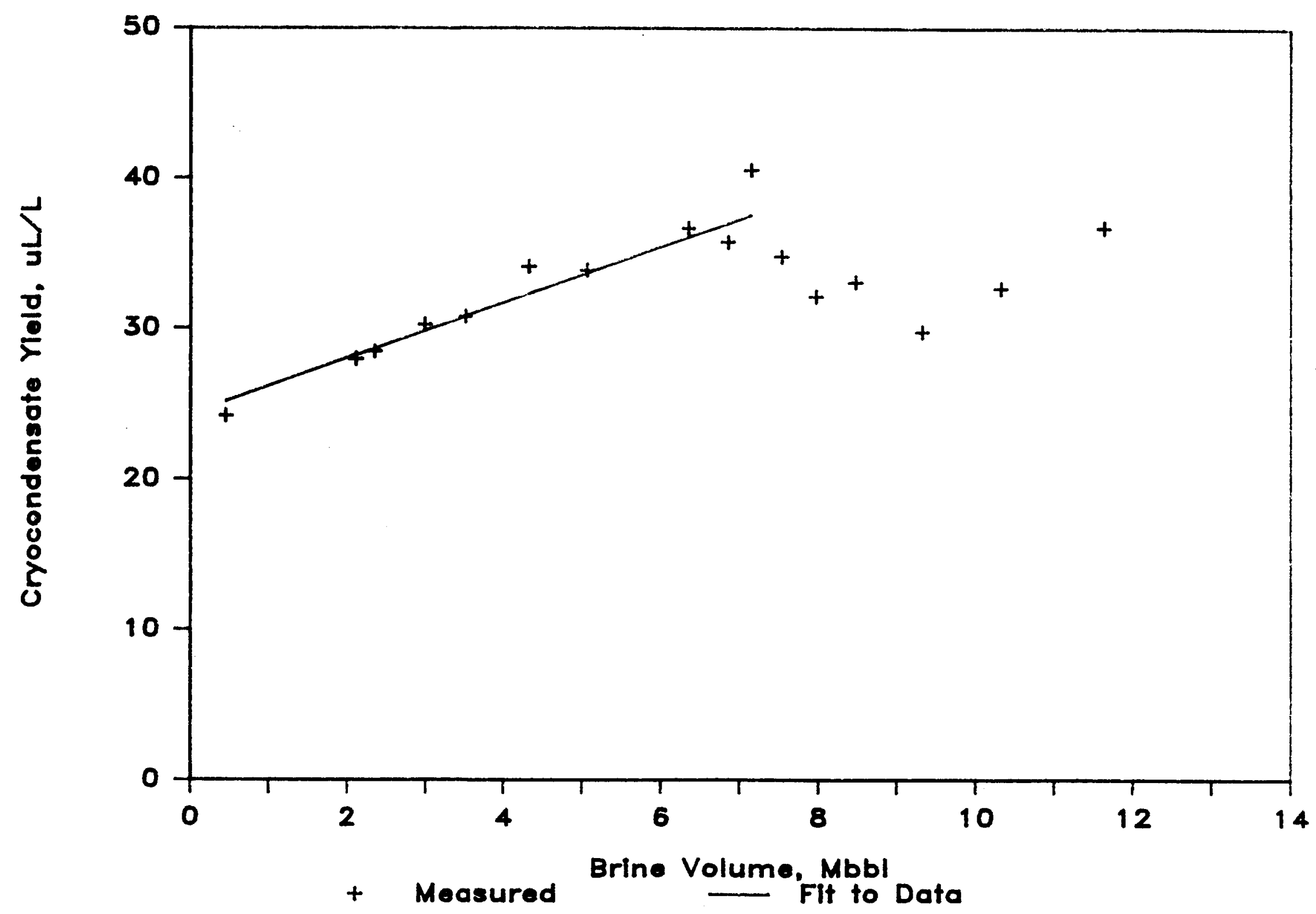




\section{Gladys McCall Well}

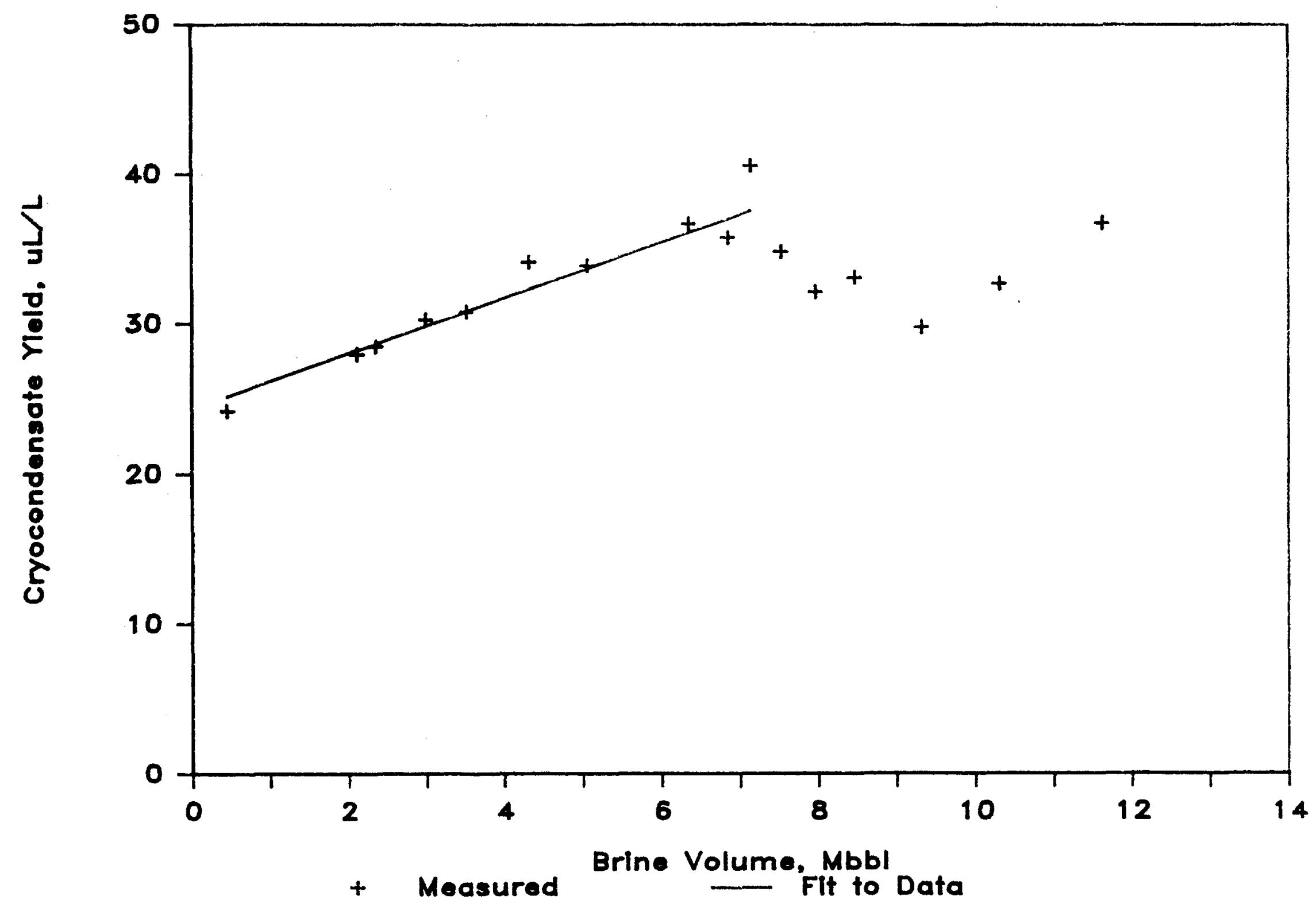


Gas chromatographic mass spectrometry analysis was carried out on cryocondensate samples from the L.R. Sweezy \#1 (L.R.S.), Pleasant Bayou \#2 (P.B.), Amoco Fee \#1 (A.F.), and Gladys McCall \#1 (G.M.) geopressured wells. A summary of the results is given in Table II.

The Gladys McCall sample labelled $\mathrm{K}-8 / 84$ is a sample of the material continually produced at the well site when the gas from the separator is passed through the gas cooler. It is essentially a cryocondensate sample in which the heavier, less volatile, components have been concentrated.

In the various cryocondensates, ninety-five components have been characterized whose peak areas are at least $1 \%$ of the peak area of the most abundant component, benzene. These ninety-five components are primarily the seven aromatic compounds benzene, biphenyl, indene, naphthalene, fluorene, anthracene, and phenanthrene and/or their derivatives. Interestingly these are the same compounds which were reported by Eaton (1981) for the Lear-G.M. Koelemay \#1 we11, a well of opportunity.

The observed increase in concentration of aromatic hydrocarbons in the brine from the Gladys $\mathrm{McCa}$ ll well up to February, 1985 is reminiscent of the observations by Zarrella and co-workers (1967) who reported that the concentration of benzene in brine from an oil bearing formation 
Table Ir. Cryogenic Condensate Componets. G.M. = Gladys Mc Call Well, A.F. = Amoco Fee Well, P.B. = Pleasant Bayou Well, L.R.S. = L.R. Sweezy (Parcperdue) Well

Most Probable Identification

Hexane isomer*

Hexane isomer*

Hexane isomer*

Hexene*

Benzene

Cyclohexane

Methylcyclohexane

Toluene

Dimethylcyclohexane*

Dimethylcyclohexane*

Dimethylcyclohexane*

Ethylcyclohexane

Trimethylcyclohexane*

p-xylene

o/m-xylene

Ethylbenzene

Methylethylbenzene isomer*

C3-cyclohexane*

Propylbenzene

Methylethylbenzene isomer*

Methylethylbenzene isomer*

Trimethylbenzene isomer*

C3-alkylbenzene*

Trimethylbenzene isomer*

C4-alkylbenzene*

C4-alkylbenzene*

C3-alkylbenzene*

C4-alkylbenzene*

C4-alkylbenzene*

$2,3-$ dihydroindene

C4-alkylbenzene*

C4-alkylbenzene*

C4-alkylbenzene*

C4-alkylbenzene*

C4-alkylbenzene*

C4-alkylbenzene*

C4-alkylbenzene*

C4-alkylbenzene*

Methyldihydroindene*

C4-alkylbenzene*

C4-alkylbenzene*

C4-alkylbenzene*
G.M. G.M. G.M. A.F. P.B. L.R.S. $3 / 84 \quad 10 / 84 \mathrm{~K}-8 / 84 \quad 3 / 84 \quad 3 / 83 \quad i / 83$

$\begin{array}{llllll} & & & & & \\ & \mathrm{X} & & & & \\ \mathrm{X} & \mathrm{X} & & & & \\ \mathrm{X} & \mathrm{X} & \mathrm{X} & \mathrm{X} & \mathrm{X} & \mathrm{X} \\ \mathrm{X} & \mathrm{X} & \mathrm{X} & \mathrm{X} & \mathrm{X} & \mathrm{X} \\ \mathrm{X} & \mathrm{X} & \mathrm{X} & \mathrm{X} & \mathrm{X} & \mathrm{X} \\ \mathrm{X} & \mathrm{X} & \mathrm{X} & \mathrm{X} & \mathrm{X} & \mathrm{X} \\ \mathrm{X} & \mathrm{X} & & & \mathrm{X} & \\ \mathrm{X} & \mathrm{X} & & & & \\ \mathrm{X} & & & & & \\ \mathrm{X} & \mathrm{X} & \mathrm{X} & & \mathrm{X} & \mathrm{X} \\ \mathrm{X} & & & & & \\ \mathrm{X} & \mathrm{X} & \mathrm{X} & \mathrm{X} & \mathrm{X} & \mathrm{X} \\ \mathrm{X} & \mathrm{X} & \mathrm{X} & \mathrm{X} & \mathrm{X} & \mathrm{X} \\ \mathrm{X} & \mathrm{X} & \mathrm{X} & \mathrm{X} & \mathrm{X} & \mathrm{X} \\ \mathrm{X} & \mathrm{X} & \mathrm{X} & \mathrm{X} & \mathrm{X} & \mathrm{X} \\ & & & & & \mathrm{X} \\ \mathrm{X} & \mathrm{X} & \mathrm{X} & \mathrm{X} & \mathrm{X} & \mathrm{X} \\ \mathrm{X} & \mathrm{X} & \mathrm{X} & \mathrm{X} & \mathrm{X} & \mathrm{X} \\ \mathrm{X} & \mathrm{X} & \mathrm{X} & \mathrm{X} & \mathrm{X} & \mathrm{X} \\ \mathrm{X} & \mathrm{X} & \mathrm{X} & \mathrm{X} & \mathrm{X} & \mathrm{X} \\ \mathrm{X} & \mathrm{X} & \mathrm{X} & \mathrm{X} & \mathrm{X} & \mathrm{X} \\ \mathrm{X} & \mathrm{X} & \mathrm{X} & \mathrm{X} & \mathrm{X} & \mathrm{X} \\ \mathrm{X} & & & & \mathrm{X} & \\ \mathrm{X} & & & & \mathrm{X} & \\ \mathrm{X} & \mathrm{X} & \mathrm{X} & \mathrm{X} & \mathrm{X} & \mathrm{X} \\ \mathrm{X} & & & & \mathrm{X} & \\ \mathrm{X} & & & & \mathrm{X} & \\ \mathrm{X} & \mathrm{X} & & \mathrm{X} & \mathrm{X} & \\ \mathrm{X} & & & & & \end{array}$


Tabie II. Continued

Most Probable

G.M. G.M. G.M. A.F. P.B. L.R.S.

Identification

$\begin{array}{llllll}3 / 84 & 10 / 84 & K-8 / 84 & 3 / 84 & 3 / 83 & 1 / 83\end{array}$

C4-alkylbenzene*

C4-alkylbenzene*

Methyldihydroindene*

Methyldihydroindene*

C4-alkylbenzene*

Tetrahydronaphthalene

Naphthalene

$2,3-$ dihydrodimethy indene*

2-methylnaphthalene*

1-methylnaphthalene*

$\begin{array}{llllll}\mathrm{X} & & & & & \\ \mathrm{X} & & & & & \\ \mathrm{X} & \mathrm{X} & & & & \\ \mathrm{X} & & & & & \\ \mathrm{X} & \mathrm{X} & \mathrm{X} & & & \\ \mathrm{X} & & \mathrm{X} & & \mathrm{X} & \\ \mathrm{X} & \mathrm{X} & \mathrm{X} & \mathrm{X} & \mathrm{X} & \mathrm{X} \\ \mathrm{X} & \mathrm{X} & \mathrm{X} & & & \\ \mathrm{X} & \mathrm{X} & \mathrm{X} & \mathrm{X} & \mathrm{X} & \mathrm{X} \\ & & \mathrm{X} & & \mathrm{X} & \mathrm{X} \\ & & \mathrm{X} & & \mathrm{X} & \\ & & \mathrm{X} & & & \\ & & \mathrm{X} & & \mathrm{X} & \\ & & \mathrm{X} & & \mathrm{X} & \\ & & \mathrm{X} & & \mathrm{X} & \\ & & \mathrm{X} & & \mathrm{X} & \end{array}$

Cyclohexylbenzene

Biphenyl

Ethylnaphthalene*

Dimethylnaphthalene isomer*

Dimethylnaphthalene isomer*

Dimethylnaphthalene isomer*

Dimethylnaphthalene isomer*

Dimethylnaphthalene isomer*

Ethylnaphthalene isomer*

Methylbiphenyl isomer*

Methylbiphenyl isomer*

Dibenzofuran

Trimethylnaphthalene isomer*

Trimethylnaphthalene isomer*

Trimethylnaphthalene isomer*

Trimethylnaphthalene isomer*

9 H-fluorene

Trimethylnaphthalene isomer*

Methyldibenzofuran*

Methyldibenzofuran*

Methyldibenzofuran*

Methylfluorene*

C4-naphthalene*

Phenanthrene or anthracene*

Methylphenanthrene isomer*

Methylphenanthrene isomer*

Methylphenanthrene isomer*

Methylphenanthrene isomer*

Methylphenanthrene isomer* 
decreased with distance from the oil deposit. If the Gladys McCall formation was to contain an oil deposit at some distance from the well bore or possibly at the top of the formation, then according to Zarrella's observations, there should be an increase in benzene, and presumably other aromatics, with brine production. This can be true even if cylindrical flow to the well bore occurs. The observed increase in aromatic hydrocarbons with brine volume in fact did portend that the Gladys McCall \#1 well would emulate the L.R. Sweezy \#1 well and ultimately produce crude oil. The yield of the cryocondensates decreased and became erratic (Figure 3) after oil production began and continued this way until the oil production ceased. There is indication that the yield is increasing again.

The consistency of the components in the cryocondensates from all the geopressured wells sampled, indicates a common geochemical process for the production of these materials. This process is visualized as a natural part of diagenesis that involves the oxidation of -( $\mathrm{HCH})$ - containing materials to a $-(\mathrm{CH})$ - containing substance. To be stable the latter substance is most probably either an aromatic compound and/or a condensed cyclohexane polymer. The absence of aromatic compounds in the brines and condensates of the watered-out commercial wells sampled, whose producing formations are above the geopressured zone, would seem to support 
the belief that this process would have a thermal threshold. The observation by Yen (1972) of 'aromatic sheets' in asphaltenes and resins precipitated from petroleum as well as the report by Oberlin (1974) of similar 'aromatic sheets" in amorphous kerogen supports our belief that cyclization during diagenesis is common. Whether the aromatic compounds that we observe are precursors to, or degradation products of, a cyclohexane polymer cannot be discerned.

\section{TASR 5: ALLIPHATIC HYDROCARBON MONITORING}

In early February, 1985, when the gas-brine separator at the Gladys McCall was drained, several gallons of a heavy oil was discovered. The oil found was heavier than the actual production oil since it was being steam distilled in the system. The subsequent yield of the oil was monitored; the data is presented in Figure 3. As in the case of the Sweezy well, oil production began only after a long induction period of brine production. The well is no longer producing oil and the yield of cryocondensates is increasing.

\section{TASR 6: C13/C12 ISOTOPE RATIOS}

Carbon-13/carbon-12 isotope ratios have been run on all of the different types of hydrocarbon samples that have been accumulated. This work was pursued because of curiosity concerning the origins of the hydrocarbon materials. The data from these determinations is summarized in Table III. 
These carbon isotope ratios seem to indicate that the carbon source of the aromatic hydrocarbons from the geopressured brines was of terrestrial plant origin. 
Gladys McCall Well
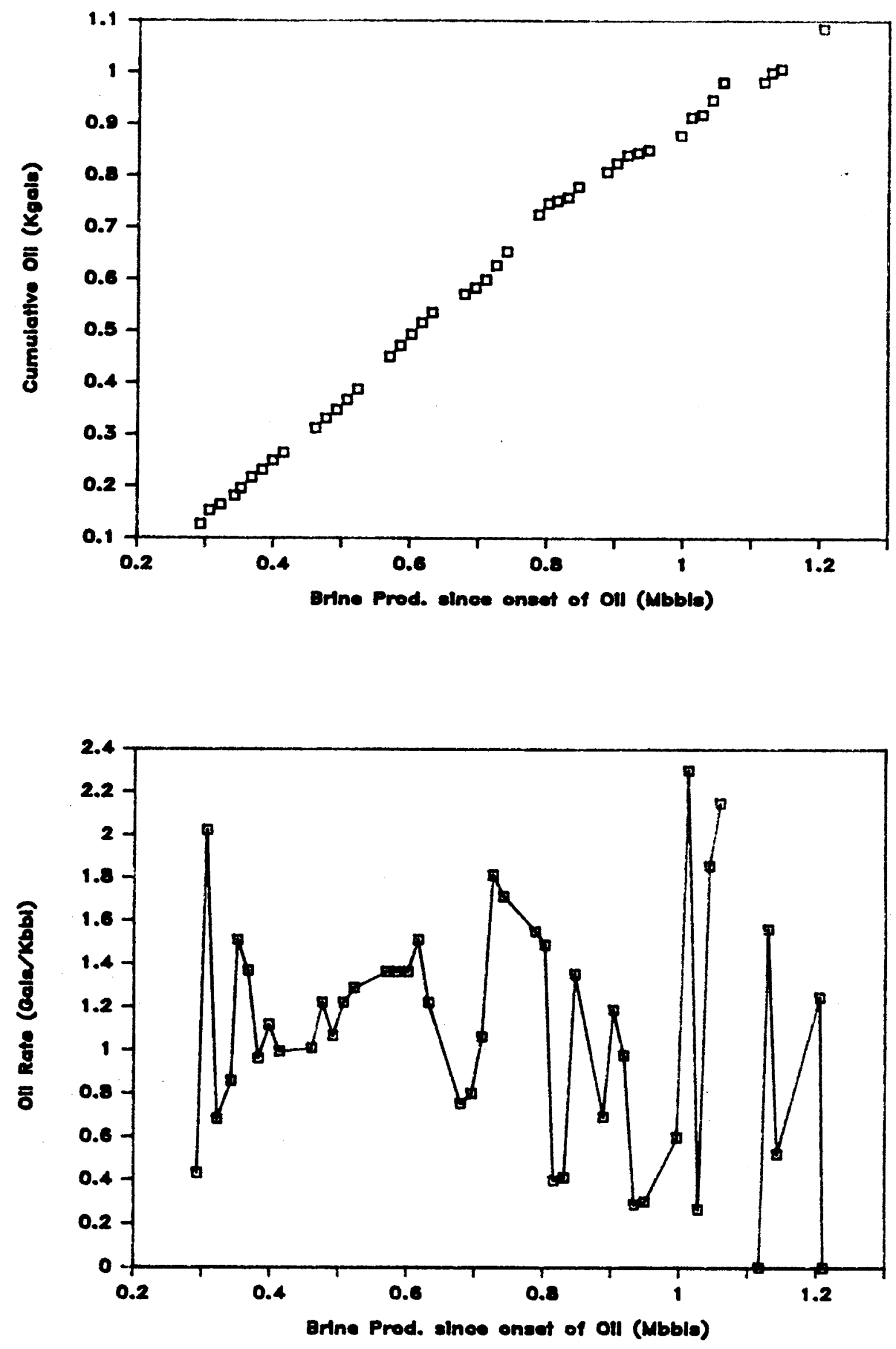

Figure 3 
TABLE III. Carbon Isotope Ratiog Relative to PDB

DOW/DOE L.R. Sweezy \#1 Well:

Cryocondensates from gas (7/13-23/82) -24.7

Light hydrocarbons from 'knock-out' trap -26.9

Heavy hydrocarbons from separator -27.1

F\&S/DOE Pleasant Bayou F2 Well:

Cryocondensates from gas (3/12/83) -26.2

Hydrocarbons from 'gun barrel' (3/12/83) -25.7

MG-T/DOE Amoco Fee \#1 Well:

$\begin{array}{ll}\text { Cryocondensates from gas } & -25.8\end{array}$

TF\&/DOE Gladys McCal1 \#1 We11:

Cryocondensates from gas, sand \#9 (3/26/83) -26.4

Hydrocarbons from gas cooler, sand $\# 9$ (3/23/83) -25.9

Cryocondensates from gas, sand $\$ 8(12 / 12 / 83) \quad-27.0$

Hydrocarbons from cooler, sand $\$ 8(12 / 12 / 83) \quad-26.2$

Flare gas, sand $\$ 8(5 / 24 / 84) \quad-41.5$

Methane, sand $\# 8(5 / 24 / 84) \quad-45.8$

G.M. Koelemay 1 Well: Data from Eaton report (1981)

Stock tank oil

$-27.4$

Flare gas $(9 / 25 / 80) \quad-48.7$

Methane $(9 / 25 / 80) \quad-49.1$ 
$\underline{\text { References }}$

Eaton Operating Company, Inc, (1981). Report to United States Department of Energy: Final Report, G.M. Koelemay Well No. 1 , Jefferson County, Texas, Volume I, Completion and Testing.

McNeese State University (1978). Report to United States Department of Energy: Geopressured-Geothermal Test of the Edna Delcambre No. 1 Well, Tigre Lagoon Field, Vermilion Parish, Louisiana.

Oberlin, A., J.L. Murand (1974a). Electron microscope investigation of the structure of naturally and artificially metamorphosed kerogen. Geochim. Cosmochim. Acta, 38, 647649.

Yen, T.F. (1972), Present status of the structure of petroleum heavy ends and its significance to various technical applications. Am. Chem. Soc, Div. Petr. Chem. (Preprint). F, 102-114.

Zarrella, K.N., R.J. Mousse6u, N.D. Coggesha11, M.S. Norris, and G.J. Schrayer (1967). Analysis and significance of hydrobcarbons in subsurface brines. Geochim. Cosmochim. Acta, 31, 1155-1166. 
THE SOLUBILITY OF AROMATIC HYDROCARBONS IN WATER AND SODIUM CHLORIDE SOLUTIONS OF DIFFERENT IONIC STRENGTHS: BENZENE AND TOLUENE.

Dean F. Keeley*, Melanie A. Hoffpauir, and John R. Meriwether Departments of Chemistry, Physics, and Acadiana Research Laboratory, University of Southwestern Louisiana, Lafayette, Louisiana 70504 
abstract

The solubilities of benzene and toluene in aqueous solutions having ionic strengths ranging from 0 to 5 have been determined at $25.00^{\circ} \mathrm{C}$. The solubilities were determined by headspace analysis using a multiple injection interrupted flow technique. The values for the Henry's law constant, partition coefficient, and activity coefficient for benzene and toluene in the solutions studied are also given. 


\section{Introduction}

The determination of the solubilities of substances which have appreciable vapor pressures is difficult. The difficulty is mechanical in nature and arises from the partition of the substance between the solvent and free gas above the solvent. The magnitude of the partition is determined by the value of Henry's law constant for the system and the relative volumes of the liquid and gas phases. Idealiy, to determine the solubility by measuring a property of the substance in solution (e.g. optical absorption) requires that all manipulations of the system be done so that no gas space is present during the procedure or that proper compensation is made for the effect of the gas space. The latter would, of course, require a knowledge of the partition coefficient of the solute and its desorption rate from solution. The wide range of solubilities reported in the literature for substances with appreciable vapor pressures, such as benzene, toluene, etc., is in part caused by these manipulative difficulties.

After reviewing the various procedures for measuring solubility reported in the literature, a modification of the headspace analysis technique employed by Massaldi and $\mathrm{King}^{1}$ was chosen. The overriding considerations in the choice, were the ease of execution of the headspace method and the impossibility of solute loss by partition between the solution and gas space. Indeed the method makes use of the partition of the solute. 


\section{Experimental}

Theoretical. In their work, Massaldi and King used volume matched 250-mL Erlenmeyer flasks as equilibration vessels. Their method consisted of adding measured volumes (of the order of microliters) of the substance of interest (specifically d-limonene, n-butylbenzene, or $n$-hexyl acetate) to a measured volume of solvent (i.e. water or aqueous sucrose solution) contained in the Erlenmeyer flasks. The volume of solute added to the flasks was incrementally increased so that in some flasks the solvent would be saturated and a third solute rich phase present. The flasks were sealed with aluminum foil and thermostated with stirring prior to analysis. Analysis of the vapor phase (i.e. headspace) was accomplished by inserting the needle of a 2-mL gas tight syringe through the aluminum foil, extracting $1 \mathrm{~mL}$ of vapor and injecting the vapor into a gas chromatograph (GC). The data was analyzed by plotting solute peak area (Massaldi and King actually plotted $A_{A} A_{0}$ where $A$ is peak area and $A_{0}$ is peak area at saturation) as a function of solute volume, $V$, added to the flask. Such a plot increases linearly at low solute volumes. The linearity is attributable to the system obeying Henry's law,

$$
p=k^{\prime} x
$$

where $p$ is the partial pressure of solute above the solution, $X$ is the mole fraction of solute in the solution, and $k^{\prime}$ is the Henry's law constant. It follows that the GC peak area, A, for 
constant volume samples is a linear function of solute in the system and obeys the relationship

$$
A=C X=C p / K^{\prime}=C K Y
$$

where $C$ is a constant which contains all pertinent GC correlation parameters, $Y$ is the mole fraction of solute in the vapor, and $K$ is the distribution coefficient for the solute in the solution and vapor (i.e. $K=X / Y$ ). For those flasks in which the solvent is saturated with solute and a third solute rich phase is present, equation 2 takes the form

$$
A^{*}=C X^{*}=C p^{*} / k^{\prime}=C K Y^{*}
$$

where starred quantities refer to values at saturation (i.e. $A^{*}$ corresponds to Massaldi's and King's $A_{0}$ values). If the solvent and all other components of the system are insoluble in the solute then the starred values refer to pure solute $\left(i . e . A^{*}=A^{0}\right.$ and $p^{*}=p^{0}$ where $p^{0}$ is the vapor pressure of pure solute). Because all solutions which contain an amount of solute at or in excess of that needed for system saturation yield the same area response, $A^{*}$ (or $A^{\circ}$ if the solute is pure) as a function of $V$ has, ideally, zero slope. This second line segment intersects the first at a solute volume corresponding to system saturation, $V_{s}$, where

$$
v_{s}=v_{x}+v_{y}
$$


in which $V_{x}$ and $V_{y}$ refer to the volume of liquid solute in the solvent and vapor respectively at saturation. If $V_{y}$ can be measured or computed then the apparent solubility (the true solubility if the solute phase is pure) can be determined.

The Masaldi and King method was modified, in part, in the way in which $V_{s}$ and $V_{y}$ were obtained. The value for the GC response at system saturation, $A^{\circ}$, was computed from the response of samples which contained only solute vapor at known partial pressures. The response at saturation was computed from this data and the vapor pressure of the solute computed from the Antoine equation,

$$
\log p=a-b /(t+c)
$$

where $t$ is the Celsius temperature and the constants $a, b$, and $c$ were those listed in Lange's Handbook of Chemistry ${ }^{2}$. The vapor pressure values from the Antoine equation are in good agreement with those used by Sanemasa, et al. ${ }^{3}$ in their calculations of the solubilities of benzene and alkylbenzenes in water.

This modification of Massaldi's and King's method has the distinct advantage of precluding the difficulties associated with the dissolution of the primary solvent (e.g. water) or any other solute (i.e. $\mathrm{NaCl}$ in our case) into the solute rich third phase that is produced following system saturation. 
Instrumentation. The experimental measurements were made using a headspace attachment which was designed and constructed ${ }^{4}$ specifically for a Varian model 3700 gas chromatograph.

Materials. All compounds used were either Baker Analyzed Reagent grade or Baker Instra-Analyzed grade. All hydrocarbons were analyzed for purity by gas chromatography prior to use. All aqueous solutions were prepared using deionized water which had a conductivity $<10^{-6}\left(\mathrm{ohm}^{\circ} \mathrm{cm}\right)^{-1}$ at $20^{\circ} \mathrm{C}$. The sodium chloride was dried at $110^{\circ} \mathrm{C}$ prior to use.

Sample Preparation. Samples were prepared in $125-\mathrm{mL}$ septum bottles (Wheaton "400" clear glass). The mean volume of these bottles was $160.10 \mathrm{~mL}$ (std dev $=+/-0.87 \mathrm{~mL}$ ) at room temperature. In this study two types of samples were used: The first sample type contained an aqueous solution and the hydrocarbon of interest and the second type contained only the hydrocarbon in an amount such that it was completely in the vapor state at $25^{\circ} \mathrm{C}$. A small $6.4 \mathrm{~mm}$ by $22.2 \mathrm{~mm}$ Pyrex glass stirring bar with a mean volume of $0.70 \mathrm{~mL}$ (Bel-Art Products) was added to those bottles which were to contain liquid. A $50-\mathrm{mL}$ aliquot of water or aqueous NaCl solution was pipeted into these sample bottles. A measured quantity of the hydrocarbon of interest was added to each bottle by means of microliter syringes (Hamilton Model 700RN) and the bottle was capped immediately so as to preclude the loss of hydrocarbon. The bottles were sealed by means of Tefion-silicone 
septa (Ace Tuf-Bond) and aluminum seals (Wheaton tear out certer style). Iin foil was placed between the Teflon-silicone septa and the contents of the bottle in order to preclude the absorption of hydrocarbon into the septa. Samples which contained only hydrocarbon were prepared in the same fashion as were the solvent containing samples. It should be noted that the presence of Teflon at any point in the experimental system can cause significant error in the result owing to absorption of hydrocarbon into the Teflon ${ }^{5}$. All manipulations were carried out in a laboratory whose temperature was maintained at $20^{\circ}$. The microliter syringes were handled as little as possible so that their temperature would not be altered and room temperature could then be used as the basis for volume to mass conversions. The densities of the brine solutions were determined by the conventional method at $20^{\circ}$ and $25^{\circ} \mathrm{C}$. Where appropriate the density ratio was employed to adjust the results from preparative to experimental temperature. The bottles were totally submerged and shaken in a thermostated bath at $25.00+/-0.01^{\circ} \mathrm{C}$ for a period of at least 72 hours prior to headspace analysis being performed. Just prior to analysis the bottles were pressurized to 1 atm with chromatographic grade nitrogen. Pressurization was accomplished through a 23-gauge hypodermic needle which was attached to the nitrogen gas line and to a Heise precision pressure gauge which had an accuracy of $+/-$ $0.0007 \mathrm{~atm}$. 
Analytical Procedure. Following pressurization the bottle was placed in a 250-mL Pyrex glass tempering beaker (Cole-Parmer) through which water at $25.0^{\circ} \mathrm{C}$ was passed from a circulator (Haake Model A82). The tempering beaker contained sufficient water in the outer chamber to cover the bottle to the aluminum seal. The bottle's septum was pierced with a side-port needle (Precision Sampling Corp.), which is an integral part of the headspace unit. The bottle and tempering beaker were supported by a magnetic stirrer (Cole-Parmer Micro-V). Vapor flow from the bottle was controlled through the headspace attachment by a fine metering valve (Nupro $M$ series with a vernier handle). The flow was maintained at a rate of $2--3 \mathrm{~mL} / \mathrm{m}$ in through a $1 \mathrm{~m}$ by $3.2 \mathrm{~mm}$ stainless steel column which contained $5 \%$ SP-1200, $1.75 \%$ Bentone34 on $100 / 120$ mesh Supelcoport (Supelco Inc.). The column was connected to a flame ionization detector (FID). In order to determine the hydrocarbon solubility, the concentration of hydrocarbon in the vapor which is in equilibrium with the hydrocarbon in solution must be known. Any vapor removal produces a pressure drop that will disturb this equilibrium. To obtain the equilibrium concentration, a multiple injection interrupted flow technique (MIIF) was developed. In this technique a series of aliquots were taken from the vapor and an extrapolation made to inftial equilibrium condition. Vapor from the bottle was allowed to flow through the GC sampling system for a specific period; the 
flow was then stopped by means of the metering valve; and after a brief pause $(\mathrm{e} . \mathrm{g} \cdot 10 \mathrm{sec})$, to allow the internal pressure of the sampling system to equilibrate, a sample was injected into the GC by means of a gas sampling valve (Valco, 6-port). The metering valve was reopened to its prior setting and vapor again allowed to flow through the sampling system for another preset time interval. The metering valve was again closed, the system allowed to come to pressure equilibrium, and a second sample injected. This procedure was repeated until a minimum of 5 samples per bottle were injected. Table 1 gives a typical time schedule for the analysis. The flow rate of GC carrier gas and the GC column temperature were adjusted so that the compound of interest would elute within the time constraints of the schedule; typically 30 $\mathrm{mL} / \mathrm{min}$ carrier flow rate and $60^{\circ} \mathrm{C}$ and $85^{\circ} \mathrm{C}$ column temperature were used for benzene and toluene respectively. The pneumatic compartment of the GC and the headspace attachment were heated to $50^{\circ} \mathrm{C}$ to preclude hydrocarbon condensation or adsorption in the system.

The sampling schedule was time coordinated with integrator events such as hydrocarbon retention time, forced baseline, etc. to assure optimum integrator operation. Figure 1 gives a typical GC response plot for one sample and table 2 gives GC response data for a typical run using the MIIF technique. As can be seen in figure 1 the peak area for each successively injected aliquot of vapor from a sample increases. This results from the pressure 
drop associated with vapor removal from the bottle and the ability of desolved hydrocarbon to be desorbed from solution in an attempt to reestablish equilibrium. A net increase in mole fraction of hydrocarbon in the vapor results since the other gases present cannot be replenished by desorption from solution. This increase in successive peak area also indicates that the rate of desorption of hydrocarbon from the stirred solutions is rapid compared to the sampling frequency.

The column headed "zero" under "Time" in table 2 indicates the value for the response at zero time (i.e. no flow) as computed from a linear least-squares analysis of the time data. The column headed "R" gives the linear correlation coefficient for the data that produced each "zero" time value.

Chromatographic analysis of the samples that contained only hydrocarbon vapor was carried out using the same procedure as that used for analysis of the hydrocarbon-water(brine) samples. However, owing to the nature of the data it was only necessary to compute the mean peak area because the absence of liquid caused peaks of essentially constant size.

Data Reduction. Treatment of the data to obtain $V_{x}$ was straightforward. The GC area response for the vapor only samples was fitted by a linear least-squares analysis as a function of added nonelectrolyte volume, $v_{v}$, to obtain 


$$
A_{v}=m_{v} v_{v}+b_{v}
$$

Using equation (6), vapor pressures, and density of the nonelectrolyte, the value of $\mathrm{A}^{0}$ was computed. A linear least-squares analysis of the solution data gave a relationship similar to that for the vapor

$$
A_{a q}=m_{a q} v_{a q}+b_{a q}
$$

At system saturation $A_{a q}=A^{0}$ and $V_{a q}=V_{s}$ and $V_{x}=V_{s}-V_{y}$ (equation 4). The ideal gas law was used to compute $V_{y}$. Figure 2 is a plot of the GC response for vapor only samples and for liquid containing samples. It is typical of the plots that were used to calculate $A^{\circ}$, the GC response for system saturation and then $V_{s}$.

Results. The solubility at $25.00^{\circ} \mathrm{C}$ for benzene and toluene in water and aqueous sodium chloride solutions with ionic strengths up to 5.00 are summarized in table 3 .

The molar activity coeficient, $f$, for a nonelectrolyte in an aqueous solution can be defined by the equation

$$
\mu=\mu^{\circ}+\operatorname{RTInfC}
$$

where the reference chemical potential of the nonelectrolyte, $\mu^{\circ}$, is the chemical potential at unit activity and $C$ is the molar concentration of the nonelectrolyte (the product $f C$ is activity, a). If the solubility is defined as the point at which the pure 
nonelectrolyte phase appears when the nonelectrolyte is incrementally added to the solvent, then the chemical potential of the nonelectrolyte is the same in all saturated solutions.

This rationale provides a way of obtaining the activity coefficient of the nonelectrolyte in solutions of different ionic strengths by measuring the solubility of the nonelectrolyte in these solutions. For two saturated solutions of different ionic strengths it follows that

$$
f_{1} / f_{2}=c_{2} / c_{1}
$$

If for one of these solutions the solvent is pure water, then

$$
s^{0} / \mathrm{s}=\mathrm{f}
$$

where $S^{0}$ and $S$ are the nonelectrolyte solubilities in water and salt solution respectively and $f$ is the activity coefficient of the nonelectrolyte in the salt solution. The values for the molar activity coefficients of benzene and toluene for solutions of different ionic strengths are given in table 4. A semilogarithmic plot of $f$ as a function of ionic strength is shown in figure 3 .

The linear correlation coefficients for the benzene and toluene plots in figure 3 are 0.998 and 0.999 respectively. This linear relationship is in accord with theoretical predictions ${ }^{6-8}$. For low nonelectrolyte concentrations it can be shown ${ }^{9}$ that a plot of In $S$ vs $C$ (or u for a 1,1 type electrolyte) should be linear. Figure 4 is a semilogarithmic plot of molar solubility as a 
function of ionic strength. The linear correlation coefficients for the data in figure 4 are 0.998 and 0.999 for benzene and toluene respectively.

An advantage of the MIIF headspace analysis method of determinIng solubility is that the headspace method does not require that the solution ever really be saturated. This precludes the difficulty of having the pure solute phase present at saturation. The effect of the presence of nonsolute gas at pressures up to 2 atmospheres is estimated to be small.

Table 5 gives the least-squares fit linear equations for the solubility of benzene and toluene in aqueous $\mathrm{NaCl}$ solutions at ionic strengths ranging from 0.0 to 5.0 at $25.00^{\circ} \mathrm{C}$ and the linear equations for the molar activity coefficients determined from the solubilities. The standard deviations for these equations are also given. MIIF gives solubility relationships in solutions of differing ionic strengths which are in good agreement with theoretical predictions. The distribution, or partition coefficients, $K, \quad\left(=C_{\text {aqueous }} / C_{\text {vapor }}\right)$ for benzene and toluene as well as the Henry's law constants are listed in table 6 for the solutions studied.

Tables 7,8, and 9 list the results of this work and earlier studies of the solubilities (table 7 ), activity coefficients (table 8), and distribution coefficients (table 9) for benzene and for toluene in water at $25.00^{\circ} \mathrm{C}$. 
Acknowledgments. This work was supported by the United States Department of Energy under Contract No. DE-AS08-83NV10338. The authors would like to express their appreciation to Drs. Richard S. Perkins and Robert D. Braun of the Chemistry Department for many helpful discussions during the course of this investigation and to Ms. Michelle M. Geraghty and Ms. Emine Ercikan for their help in obtaining the data. 
(1) Massald1, H.A.; King, C.J. J. Chem. Eng. Data 1973, 18(4), 393.

(2) "Lange's Handbook of Chemistry", 12th ed.; Dean J.A., Ed.; McGraw-Hill: New York, 1979; p 10-28.

(3) Sanemasa, I.; Araki, M.; Deguchi, T.; Nagai, H. Bulle Chem. Soc. Jen. $1982,55,1054$.

(4) Keeley, D.F., submitted for publication in Rev. Sci. Instrum.

(5) Keeley, D.F.; Hoffpauir, M.A.; Meriwether, J.R., Submitted for publication in Anale chem.

(6) Debye, P.; McAulay, J. Physik. Z. 1925, 26, 22.

(7) Debye, P. Z, physik, Chem. 1927, 130, 56.

(8) Butler, J.A.V. J. Phys, cheme 1929, 33, 1015.

(9) Long, F.A.; McDevit, W.F. Chem. Revs, 1952, 51, 119.

(10) Andrew, L.J.; Keefer, R.M. Le Am. Cheme Soc. 1949, 71, 3644.

(11) Klevens, H.B. J Rhys, Colloid. Chem. 1950, 54, 283.

(12) Bohon, R.L.; Clausen, W.F. J. Am. Chem. Soc. 1951, 13, 1571.

(13) Hayashi, H.; Sasaki, T. Bulde Chem. Soc, Jon, 1956, 29, 857.

(14) Arnold, D.S.; Plank, C.A.; Erickson, E.E.; Pike, F.P. Chem. Eng, Data Ser. 1958, 3, 253.

(15) McAuliffe, C. J. Phys, Chem, 1966, 70, 1267.

(16) Taha, A.A.; Grisby, R.D.; Johnson, J.R.; Christian, S.D.; Affsprung, H.E. Le Cheme Educ. 1966, 43, 432.

(17) Worley, J.D. Can. I. Chem. 1967, 45, 2465.

(18) Polak, J.; Lu, B.C.Y. Can. J. Chem. 1973, 51, 4018. 
(19) Price, L.C. Ph.D. Dissertation, University of California, Riverside, Calif., 1973.

(20) Mackay, D.; Shiu, W.Y. Can. J. Cheme Eng. 1975, 53, 239.

(21) Sutton, C.; Calder, J.A. J. Chem. Eng. Data 1975, 20, 320.

(22) Schwarz, F.P. Anal, Chem, 1980, 52, 10.

(23) Green, W.J.; Frank, H.S. J. Solut Chem. 1979, 8, 187.

(24) Mackay, D.; Shiu, W.Y.; Sutherland, R.P. Environ. Scie Technol. 1979, 13, 333.

(25) Tsibulski1, V.V.; Tsibulskaya, I.A.; Yaglitskaya, N.N. Zhe Analit. Khim. 1979, 34, 1364. 
Table 1. Typical GC Sampling Schedule for Multiple Injection Interrupted Flow (MIIF) Technique

Time, minutes:seconds Event(s)

$\begin{array}{ll}0: 00 & \text { Start clock \& integrator, open metering valve } \\ 2: 00 & \text { Close metering valve } \\ 2: 10 & \text { Inject sample } \\ 2: 30 & \text { Open metering valve } \\ 3: 30 & \text { Close metering valve } \\ 3: 40 & \text { Inject sample } \\ 4: 00 & \text { Open metering valve } \\ 5: 00 & \text { Close metering valve } \\ 5: 10 & \text { Inject sample } \\ \text { in } & \text { Close metering valve } \\ n: 00 \text { or } 30 & \text { Inject sample } \\ n: 10 \text { or } 40 & \text { Open metering valve } \\ n: 30 \text { or } 00 & \text { C }\end{array}$




Table 2. GC Response for Benzene in $50.0 \mathrm{~mL}$ of Water at $25.00^{\circ} \mathrm{C}$
$\begin{gathered}\text { Solute, } \\
\text { uL }\end{gathered}$
\begin{tabular}{ccccccccc} 
\\
20 & 375364 & 375584 & 380089 & 380133 & 384016 & 370296 & 0.953 \\
40 & 717290 & 725721 & 738283 & 748453 & 760444 & 694422 & 0.998 \\
60 & 1165999 & 1172964 & 1180987 & 1188330 & 1195316 & 1151119 & 0.999 \\
80 & 1574147 & 1585170 & 1587167 & 1597830 & 1604989 & 1560123 & 0.986 \\
100 & 2001901 & 2014959 & 2026739 & 2039772 & 2049375 & 1978645 & 0.999 \\
\hline
\end{tabular}


Table 3. Solubility of Benzene and Toluene in Aqueous Solutions of Different Ionic Strengths at $25.00^{\circ} \mathrm{C}$

\begin{tabular}{|c|c|c|c|}
\hline $\begin{array}{l}\text { Ionic } \\
\text { Strength }\end{array}$ & $\mathrm{Ppm}^{\mathrm{a}}$ & $\begin{array}{l}10^{4} \cdot \text { Mole fraction } \\
\text {..... Benzene..... }\end{array}$ & $10^{2} \cdot \mathrm{Mole} / \mathrm{L}^{\mathrm{a}}$ \\
\hline 0 & $1547(11)$ & $3.564(0.026)$ & $1.974(0.014)$ \\
\hline 1 & 1068 (3) & $2.562(0.007)$ & $1.416(0.004)$ \\
\hline 2 & $688(10)$ & $1.716(0.026)$ & $0.945(0.014)$ \\
\hline 3 & $446(16)$ & $1.155(0.041)$ & $0.633(0.023)$ \\
\hline 4 & $266 \quad(7)$ & $0.713(0.019)$ & $0.388(0.010)$ \\
\hline 5 & 168 (13) & $\begin{array}{c}0.467(0.035) \\
\ldots . . \text { Toluene..... }\end{array}$ & $0.253(0.019)$ \\
\hline 0 & $562(13)$ & $1.099(0.026)$ & $0.609(0.014)$ \\
\hline 1 & $316(12)$ & $0.643(0.023)$ & $0.355(0.013)$ \\
\hline 2 & 191 (5) & $0.403(0.011)$ & $0.222(0.006)$ \\
\hline 3 & $97.9(8.3)$ & $0.215(0.018)$ & $0.118(0.010)$ \\
\hline 4 & $52.9(4.6)$ & $0.120(0.010)$ & $0.0656(0.0026)$ \\
\hline
\end{tabular}

a standard deviation of the mean in parentheses 


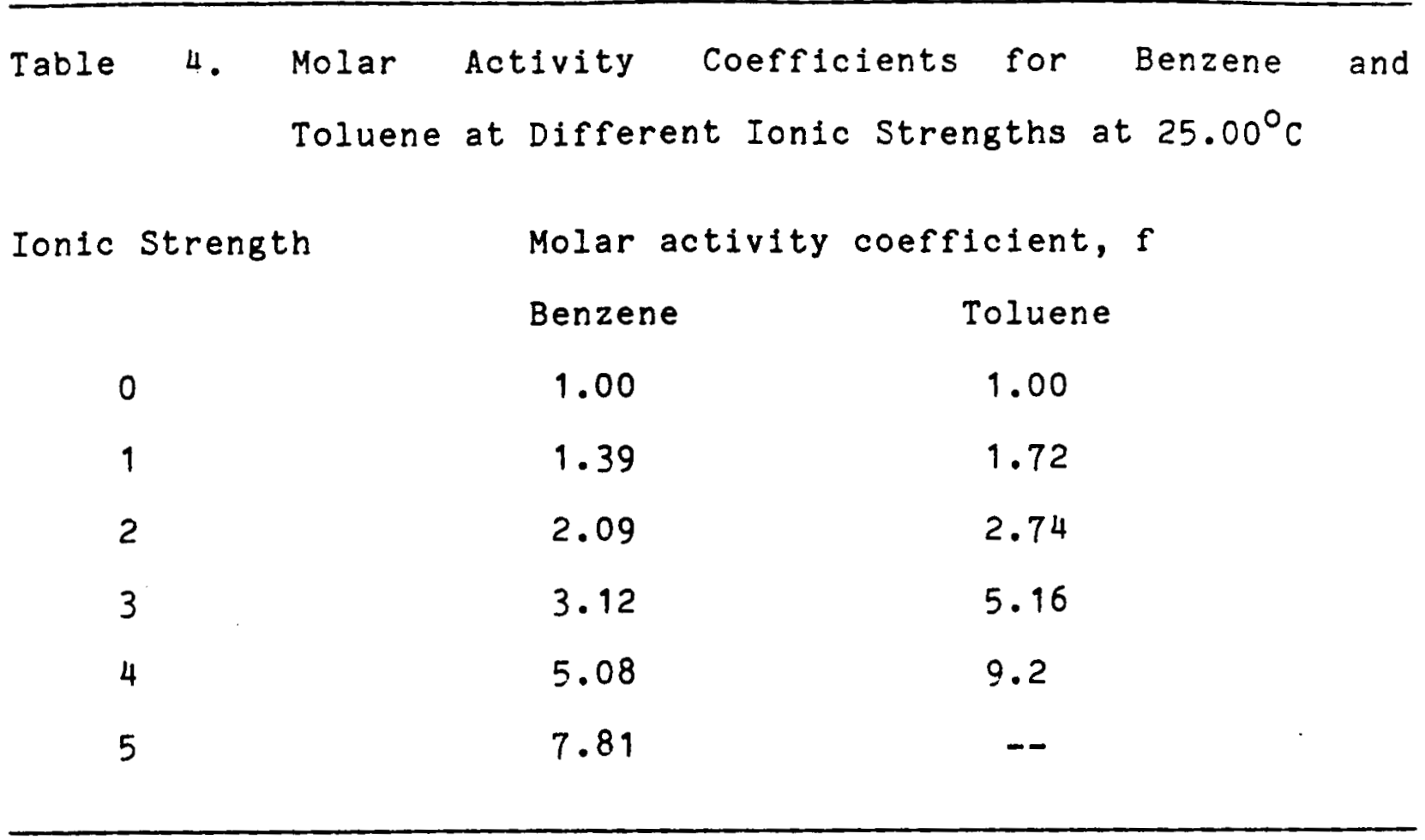


Table 5. Least-Squares Fit Equations for the Molar Solubilities and Molar Activity Coefficients of Benzene and Toluene in Aqueous $\mathrm{NaCl}$ Solutions at $25.00^{\circ} \mathrm{C}$

$$
\text { .....Molar Solubility..... }
$$

$\begin{array}{lll}\text { Benzene } & - \text { In } S=0.416 \mu+3.866 & \text { std dev }=0.0441 \\ \text { Toluene } & - \text { In } S=0.556 \mu+5.073 & \text { std dev }=0.0435 \\ \text { Benzene } & \text { In } f=0.416 \mu-0.0596 & \text { std dev }=0.0441 \\ \text { Toluene } & \text { In } f=0.556 \mu-0.0272 & \text { std dev }=0.0441\end{array}$


Table 6. Distribution (Partition) Coefficients, $K^{a}$, and Henry's Law Constants, $k^{\prime}$, of Benzene and Toluene in Aqueous $\mathrm{NaCl}$ Solutions of Various Ionic Strengths at $25.00^{\circ} \mathrm{C}$

\section{Benzene}

\begin{tabular}{|c|c|c|c|c|}
\hline $\begin{array}{c}\text { Ionic } \\
\text { strength }\end{array}$ & $\mathrm{K}$ & $10^{-5} \cdot k^{\prime}$, torrs & $\mathrm{K}$ & $10^{-5} \cdot \mathrm{k}^{\prime}$, torrs \\
\hline 0 & $3.84(0.03)$ & $2.67(0.02)$ & $3.97(0.09)$ & $2.59(0.06)$ \\
\hline 1 & $2.76(0.01)$ & $3.72(0.01)$ & $2.31(0.08)$ & $4.43(0.16)$ \\
\hline 2 & $1.84(0.03)$ & $5.55(0.08)$ & $1.45(0.04)$ & $7.06(0.19)$ \\
\hline 3 & $1.23(0.04)$ & $8.25(0.29)$ & $0.767(0.065)$ & $13.25(1.12)$ \\
\hline 4 & $0.756(0.020)$ & $13.36(0.36)$ & $0.427(0.017)$ & $23.63(1.88)$ \\
\hline 5 & $0.492(0.037)$ & $20.39(1.54)$ & -- & $-\infty$ \\
\hline & $\mathrm{K}=\mathrm{C}_{\text {aqueous }}$ & vapor & & \\
\hline
\end{tabular}

Toluene 
Table 7. Reported Values for the Molar Solubility of Benzene and/or Toluene in water at $25.00^{\circ} \mathrm{C}$

Reference

This work: Experimental values

Best fit equation (table 5)

Andrew and Keefer ${ }^{10}$

Klevens ${ }^{11}$

Bohon and Clausen 12

Hayashi and Sasaki ${ }^{13}$

Arnold et al. 14

McAuliffe 15

Taha et al. 16

Worley ${ }^{17}$

Polak and $\mathrm{Lu}^{18}$

Price ${ }^{19}$

Mackay and Shiu 20

Sutton and Calder 21

Schwarz 22

Sanemasa et al. 3
Solubility, $10^{2} \cdot$ Mole/L Benzene Toluene

$1.974 \quad 0.609$

$2.094 \quad 0.626$

2.23

0.58

2.38

0.54

2.29

0.681

2.30

2.23

2.279

0.5599

2.2

2.78

2.247

0.622

0.601

2.2782

0.5639

0.5805

2.33-

0.716 -

2.47

0.727

2.06

0.561 
Table 8. Reported Values for the Henry's Law Constant for Benzene and/or Toluene in water at $25.00^{\circ} \mathrm{C}$

Reference

$10^{-5} \cdot k^{\prime}$, torrs

Benzene Toluene

This work

2.67

2.59

Taha et al. 16

2.40

Green and Frank 23

2.30

Mackay et al. 24

2.35

2.81 
Table 9. Reported Values for the Distribution Coefficient, $\mathrm{K}^{\mathrm{a}}$, for Benzene and Toluene in Water at $25.00^{\circ} \mathrm{C}$

Reference

Benzene Toluene

This work

Tsibulskil et al. 25
3.84

4.0 3.97

3.6

$a^{K}=c_{\text {water }} / C_{\text {vapor }}$ 
Figure 1. Typical GC response for five successive aliquots of vapor from the same liquid containing sample bottle at $25.00^{\circ} \mathrm{C}$ using the MIIF technique.

Figure 2. Typical "zero" flow time GC response as a function of microliters of hydrocarbon added to the sample bottle. 0 = vapor only samples. $\bullet$ = liquid containing samples. Dashed line is the computed response at system saturation.

Figure 3. Logarithm of the molar activity coefficient of benzene and toluene as a function of lonic strength at $25.00^{\circ} \mathrm{C}$. 0 = benzene and $\bullet$ = toluene.

Figure 4. Logarithm of the molar solubility of benzene and toluene as a function of ionic strength at $25.00^{\circ} \mathrm{C}$. 0 = benzene and $\bullet$ = toluene. 


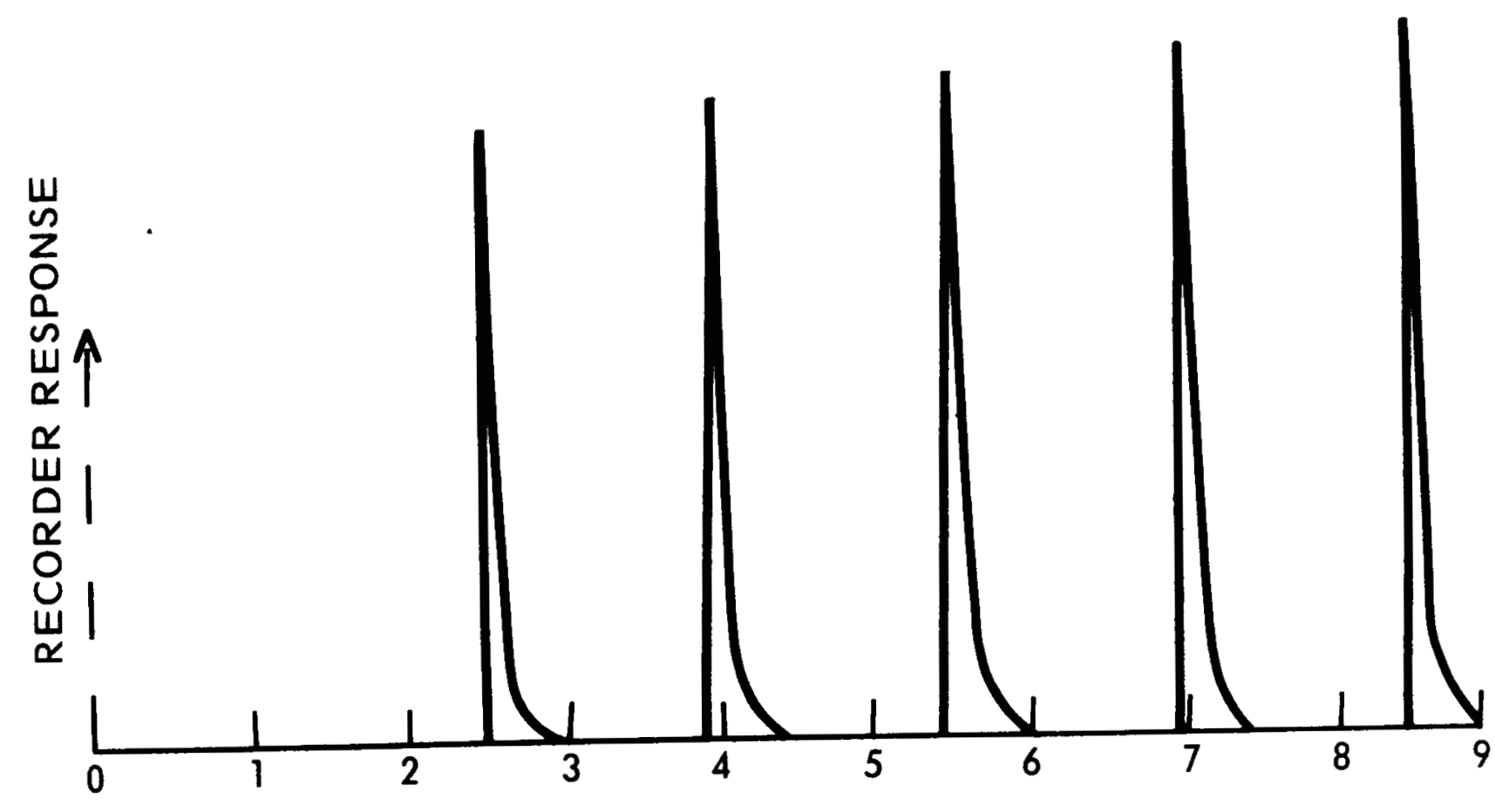

TIME (MIN) 


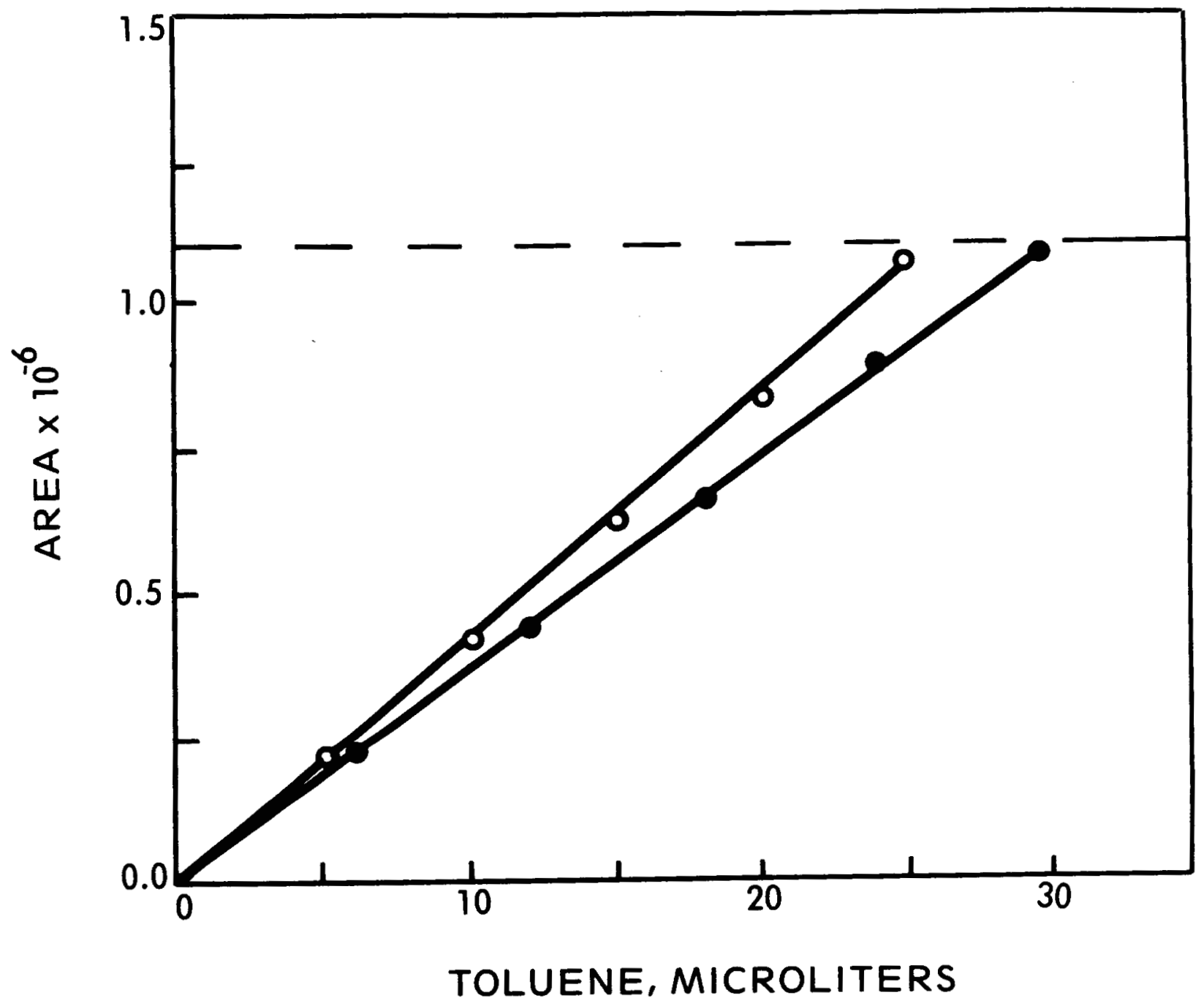




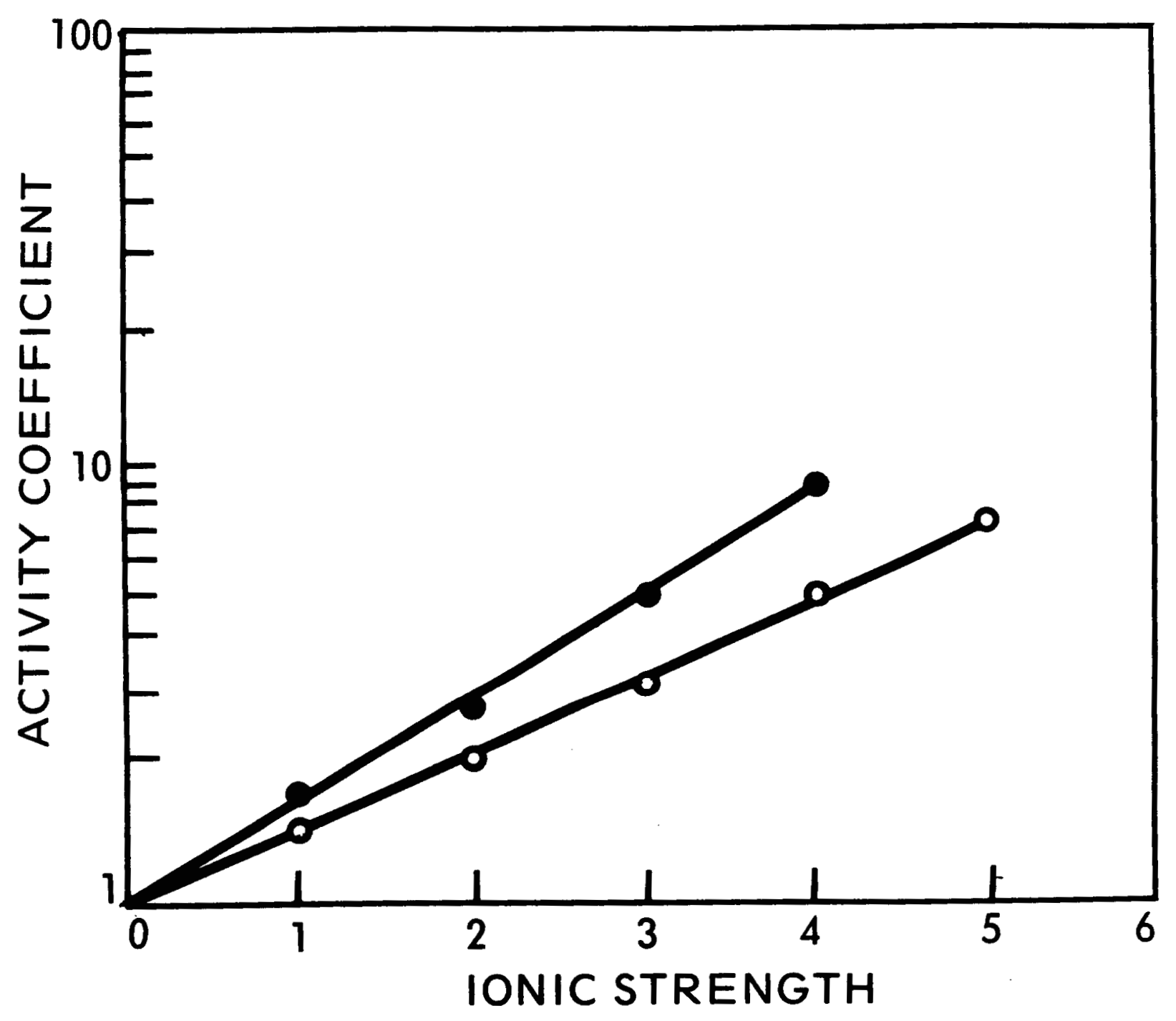




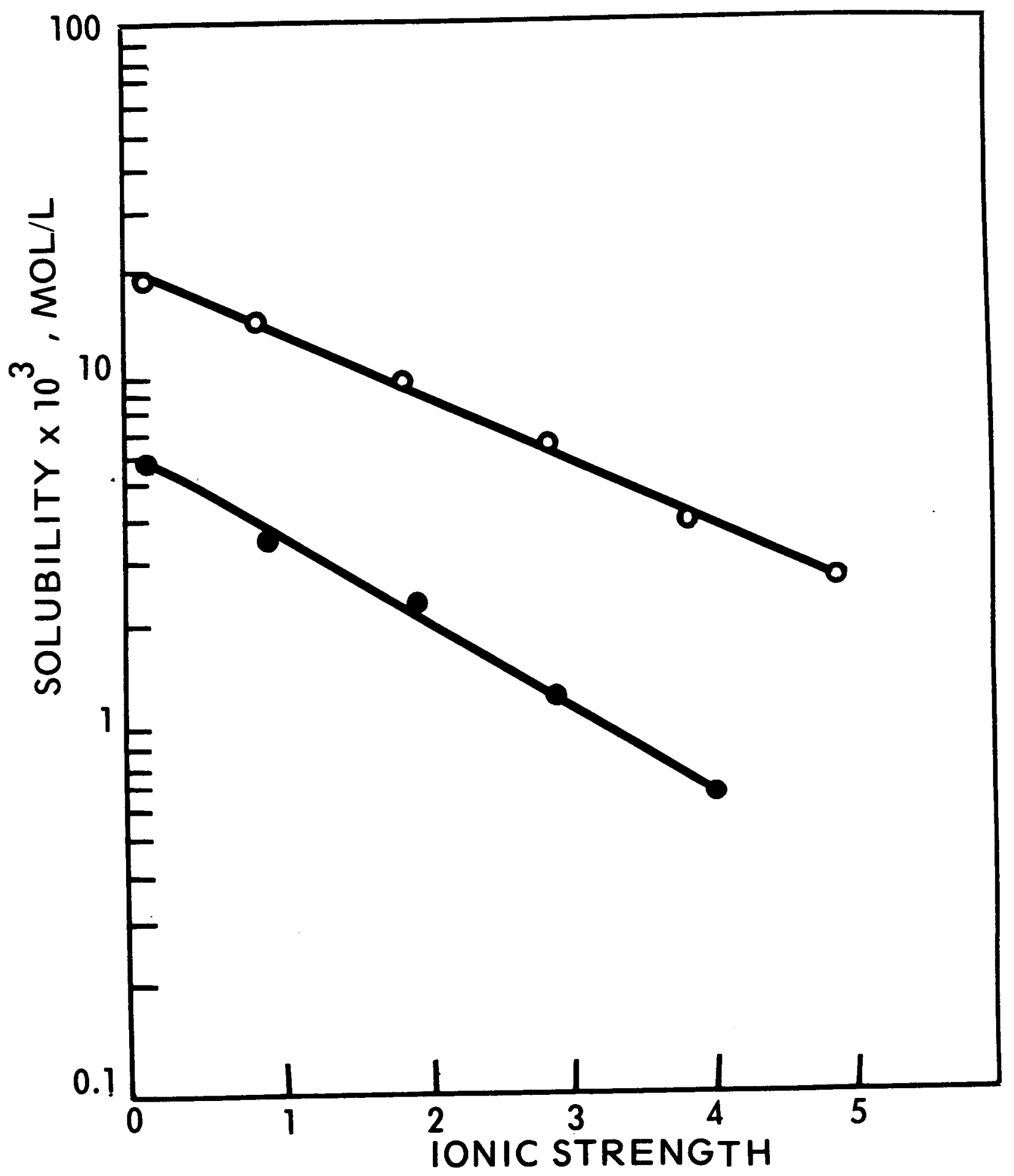


Headspace attachment for a Varian model 3700 gas chromatograph Dean F. Keeley* and John R. Meriwether

Departments of Chemistry, Physics, and Acadiana Research Laboratory, University of Southwestern Louisiana, Lafayette, Louisiana 70504 
abstract

A headspace analysis attachment for a Varian model 3700 gas chromatograph is described. The attachment differs from most commercial headspace attachments in the size sample bottle that it can accommodate. Graphical data obtained using the attachment is given. 


\section{INTRODUCTION}

Headspace analysis is an analytical technique in which vapor in equilibrium with a condensed phase is analyzed. The condensed phase may contain one or more components which have appreciable vapor pressures. Analysis is generally done by gas chromatography (GC) and provides information about the composition of the vapor and through the partition coefficients, $K_{i}(=$ condensed phase concentration / vapor phase concentration), information about the composition of the condensed phase.

Most commercial headspace attachments use relatively small sample vials. The maximum size is about $25 \mathrm{~cm}^{3}$ (e.g. Perkin-Elmer model HS-100). For a $25 \mathrm{~cm}^{3}$ vial the usable volume available for the condensed phase is of the order of 10 to $15 \mathrm{~cm}^{3}$. If, as was our case, one wants to use headspace analysis to determine solubilities of volatile compounds, which have solubilities that are less than $50 \mathrm{~mm}^{3}$ per $\mathrm{dm}^{3}$ of solvent, one would have to accurately measure quantities of solute in the sub-millimeter ${ }^{3}$ range. While liquld delivery equipment having capabilities in this range is available (e.g. Gilmont Instruments, Inc.), experience has shown that a better approach is to have a headspace attachment that will accommodate larger sample vials. This need prompted us to bulld our own headspace attachment for an avallable Varian Model 3700 gas chromatograph which was already equipped with a Valco 6-port gas sampling valve. 


\section{DESIGN CRITERIA}

A headspace analysis attachment for a gas chromatograph must incorporate certain features for satisfactory operation. The criteria which dictated our design are:

1. Type and size of the sample vessel: We decided to design our attachment so that it would accommodate up to a $125 \mathrm{~cm}^{3}$ septum bottle (Wheaton "400" clear glass). The mean internal volume of these bottles is $160.10 \mathrm{~cm}^{3}$ (std dev $=+1-0.87 \mathrm{~cm}^{3}$ ) at room temperature. The bottles are sealed using septa and aluminum seals (Wheaton center tear-out style).

2. Thermostating: Our design makes use of a tempering beaker: A double walled beaker through which thermostated water is passed (Cole-Parmer Instrument Co.). The outer compartment of the beaker contains enough water to cover the sample bottle to the aluminum seal.

3. Pressurizing the sample. For design simplicity we decided to pressurize our sample separate from the headspace attachment. This is accomplished through a 23-gauge hypodermic needle which is attached by Tygon tubing to a inert gas line (i.e. helium or nitrogen) and to a Heise precision pressure gauge which has a readability of $+/-<0.1 \mathrm{kPa}$.

4. Sample injection: Our design incorporates a needle holder assembly and needle (Precision Sampling Corp., side-hole type), used to pierce the sample bottle septa, a fine metering valve (Nupro $M$ series with vernier handle) to control sample flow rate, 
and a gas sampling valve (Valco 6-port), used, in conjunction with a sample loop, to inject a constant size sample $\left(240 \mathrm{~mm}^{3}\right.$ in our system) into the GC.

5. Preventing condensation or adsorption: We use a proportional temperature controlier (YSI model 72) and thermistor probe to turn on/off a resistance heating element inside the headspace attachment. The heating device not only heats the headspace attachment but also the preumatic compartment of the GC. Temperature regulation is monitored by a mercury in glass thermometer. This technique prevents the condensation or adsorption of sample components in the tubing of the headspace attachment.

\section{CONSTRUCTION DETAILS}

Figure 1 is a schematic diagram of the headspace attachment. The attachment was constructed on a piece of $1.14-\mathrm{mm}$ stainiess steel (shown as $X$ in figure 1) which replaced the pneumatic compartment cover of the GC. Two holes approximately $10-\mathrm{cm}$ in diameter were cut in this baseplate to allow for air circulation between the attachment and the GC pneumatic chamber by means of the blower (shown as $B$ in figure 1). The remainder of the sheet metal used was $0.64-\mathrm{mm}$ stainless steel. It was cut and bent so as to form two boxes (labelled $Y$ and $Z$ in figure 1). A port was cut between the two boxes to allow for alr circulation. Holes were drilled in the boxes to allow for installation of the fine 
metering valve, sampling needle, thermistor probe, thermometer and heater and fan wiring. The inside of both boxes was lined with $1.27-\mathrm{cm}$ Ceramfab insulation. Sheet metal screws were used to assemble and attach the boxes to the main panel. The front of the upper box was removable to facilitate needle and/or sample loop replacement. The tubing used throughout the attachment was $1.6-\mathrm{mm}$ o.d. small bore stainless steel. The resistance heater was a 660-watt cone gloco1l type (Eagle Electric Mfg. Co., Inc.). Figure 2 is an exploded view of the needle assembly. Except for the needle, which is stainless steel, and the needle adapter gasket, which was machined from Kel-F, the assembly was machined from brass. For rigidity it is attached to the baseplate by means of a stainless steel bracket. It should be mentioned that due to their tendency to absorb organic compounds, the use of plastics in a headspace attachment be kept to a minimum ${ }^{1}$. Figure 3 is a drawing of the Lucite needle guide which was placed on a sample bottle prior to its attachment to the headspace unit.

Figure 4 is a perspective drawing of the headspace attachment.

\section{APPLICATIONS}

The described headspace attachment has been used for over a year to provide the experimental data to calculate the solubilities of several aromatic compounds in aqueous sodium chloride solutions which have ionic strengths ranging from 0 to $5^{2}$ (The ionic strength of a solution is defined by the relationship 


$$
\mu=1 / 2 \sum_{i} c_{i} z_{i}^{2}
$$

where $c_{i}$ is the concentration of ion $i$ in the solution expressed as mol/L and $z_{i}$ is the number of fundamental units of charge on the 1on. For a $+1,-1$ solute such as sodium chloride (i.e. $\mathrm{Na}^{+1} \mathrm{Cl}^{-1}$ ) it is equal to the solute concentration expressed in $\left.\mathrm{mol} / \mathrm{dm}^{3}\right)$. Figure 5 shows the type of GC recorder response that one obtains from several sample successively removed from a bottle containing benzene vapor. Figure 6 is a plot of integrator response for a series of five samples containing benzene vapor at different partial pressures. The linear correlation coefficient for the data in figure 6 is 0.999 .

\section{ACKNOWLEDGEMENT}

This work was supported by the United States Department of Energy under Contract No. DE-ASO8-83NV 10338. 
${ }^{1}$ D.F. Keeley and J.R. Meriwether, submitted for publication in Anale chem.

${ }^{2}$ D.F. Keeley, M.A. Hoffpauir, and J.R. Meriwether, submitted for publication in J. Bhys, chem. 
Figure 1. Schematic diagram of headspace attachment. $G=$ gas sampling valve (shown in the load position), $R=$ resistance heater, $P=$ thermistor probe, $F=$ fine metering valve, $N=$ needle assembly, $B=$ pancake blower, $C=$ proportional temperature controller, $S=$ sample loop, $v=$ vent.

Figure 2. Needle assembly. The components and the material from which they were machined are from top to bottom: mounting bracket (stainless steel) and housing plug (brass), needle adaptor gasket (Kel-F), needle (stainless steel, commercial), alignment collar (brass), housing body (brass).

Figure 3. Needle guide (Lucite).

Figure 4. Headspace attachment, perspective view. $G=$ gas sampling valve, $R=$ resistance heater, $P=$ thermistor probe, $F=$ fine metering valve, $N=$ needle assembly, $B=$ blower compartment, $C=$ to proportional temperature controlier, $S=$ sample loop, $V=$ vent, $I=$ thermometer, $A=$ air vent with baffle.

Figure 5. Typical recorder response for five aliquots from a single bottle containing benzene vapor at $25.00^{\circ} \mathrm{C}$.

Figure 6. Integrated peak area as a function of benzene vapor partial pressure at $25.00^{\circ} \mathrm{C}$. 


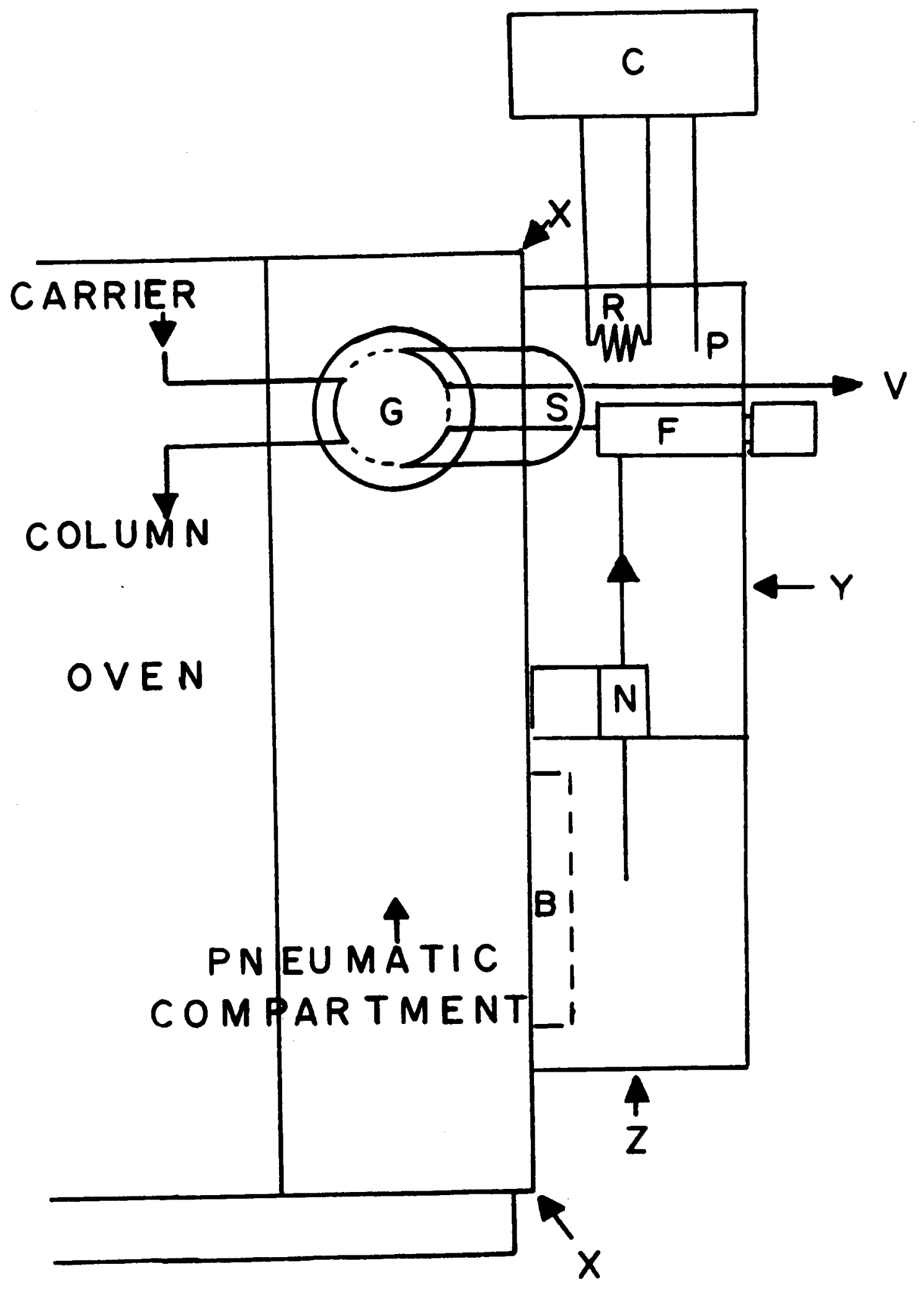




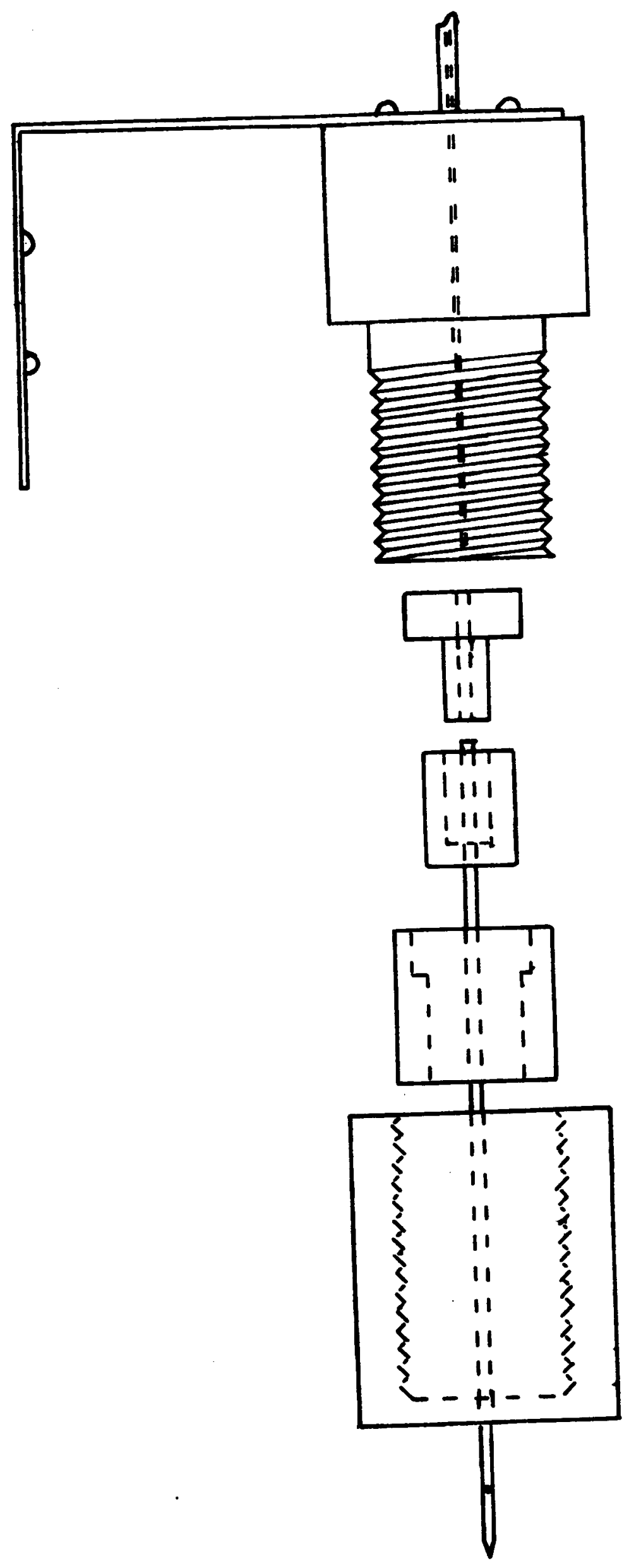


$\square$ 


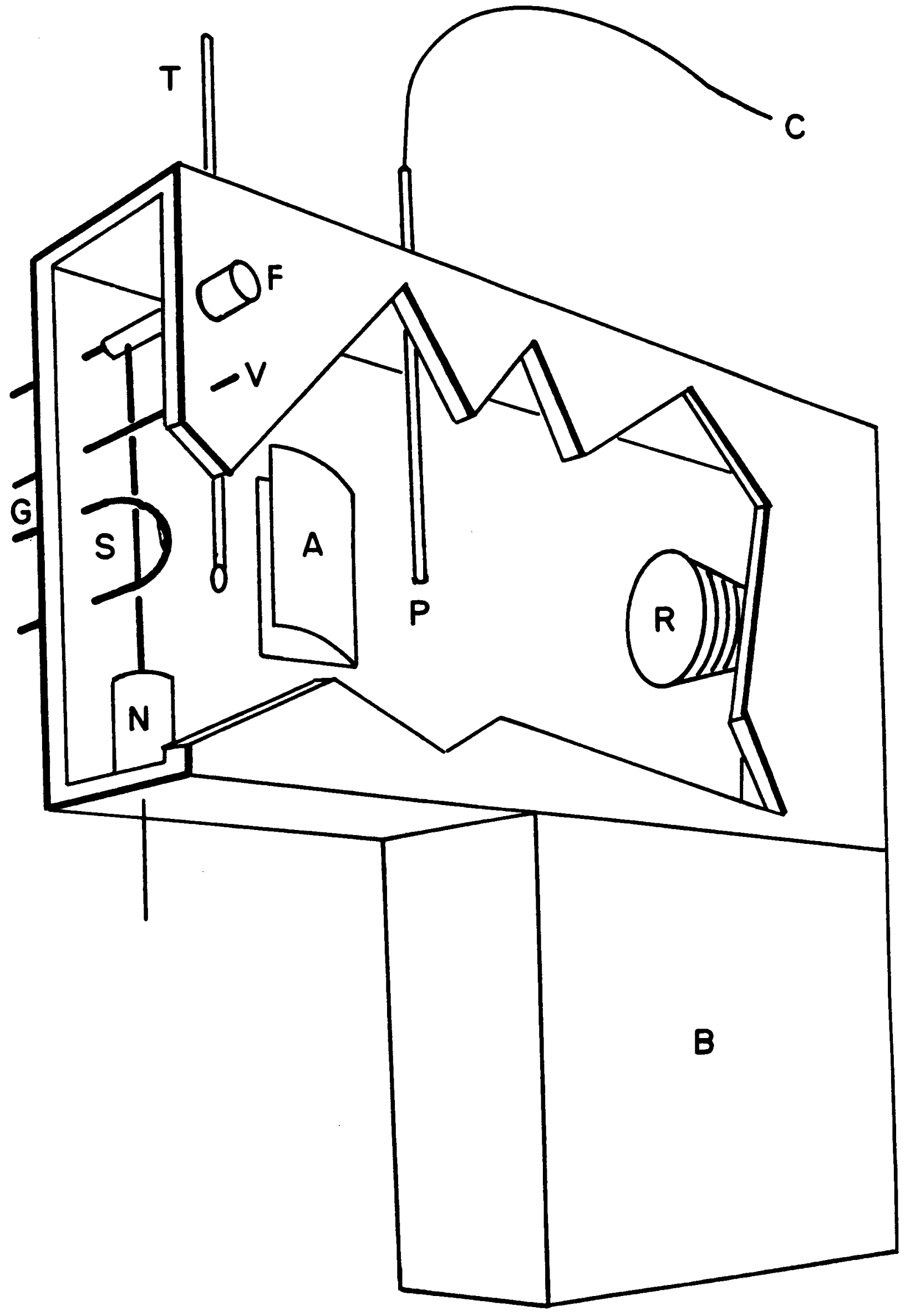




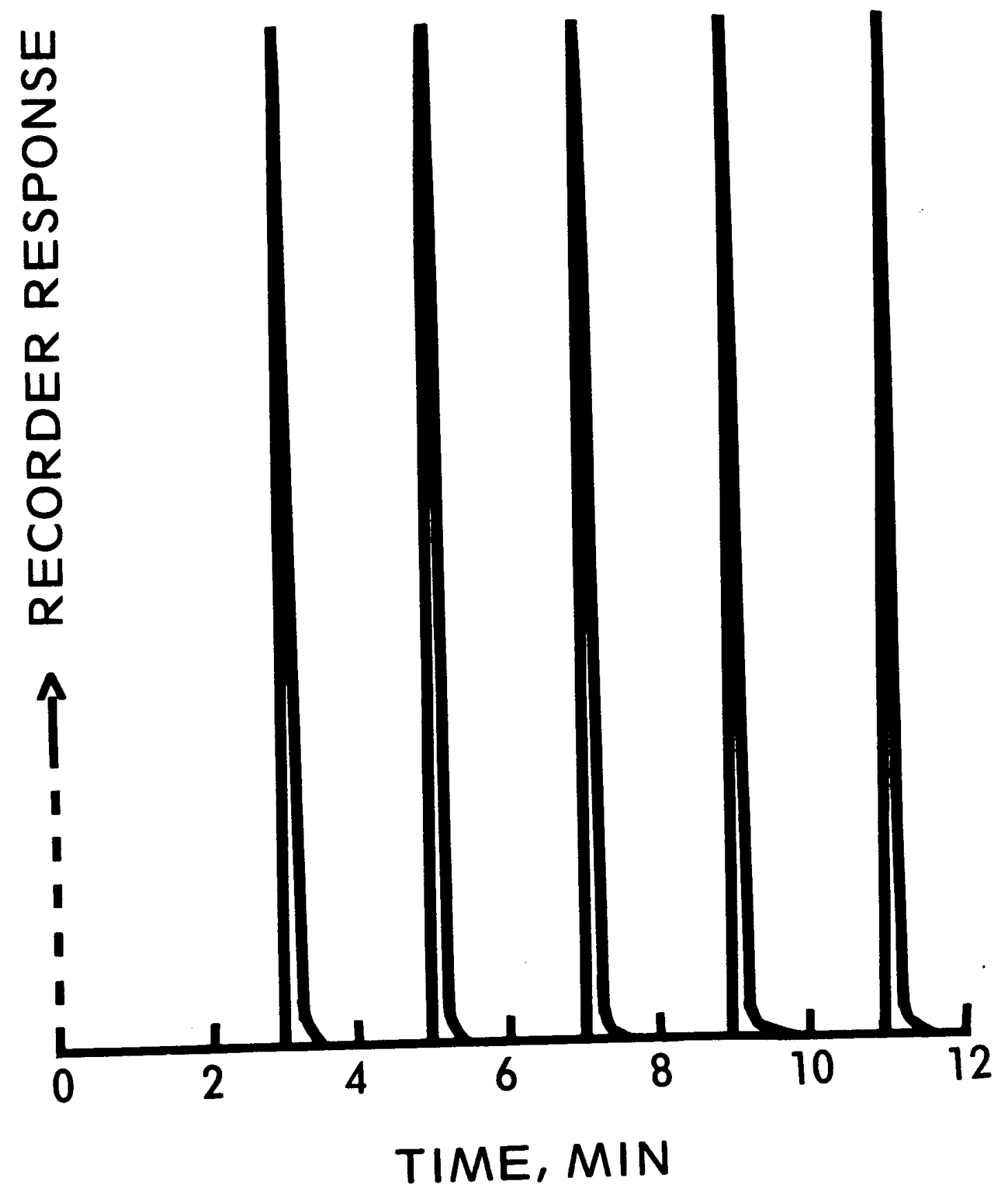




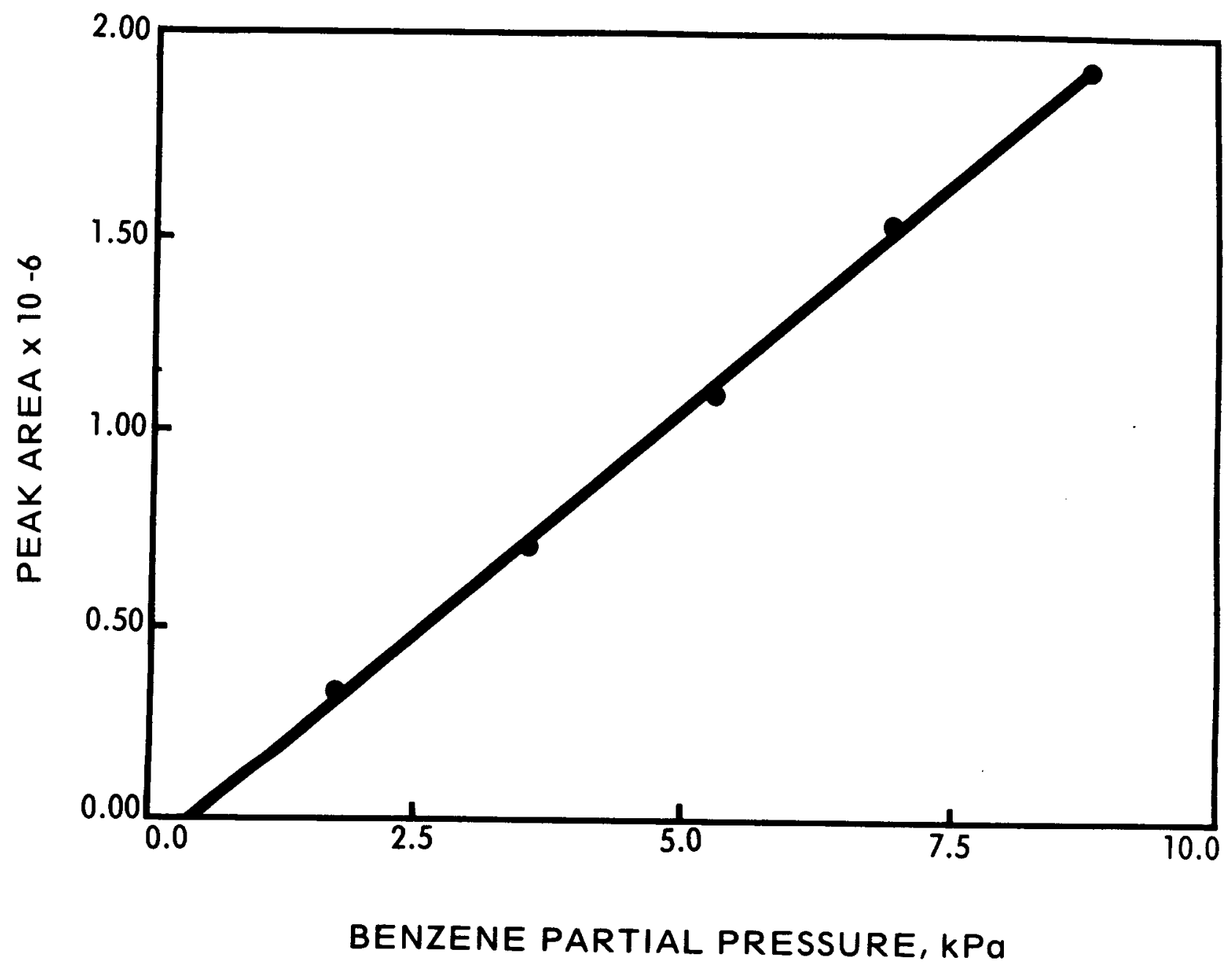

